Discussion Paper 133

Institute for Empirical Macroeconomics

Federal Reserve Bank of Minneapolis

90 Hennepin Avenue

Minneapolis, Minnesota 55480-0291

December 1999

\title{
Political Economy of Taxation in an Overlapping-Generations Economy
}

\author{
Marco Bassetto* \\ Northwestern University
}

\begin{abstract}
This paper builds a simple but complete model of a political system to analyze the effects of intergenerational conflicts on capital and labor income tax rates, transfers, and government spending. I show how the different nature of tax liabilities for the young and the old can explain why the old receive large gross lump-sum transfers through social security, while the young receive little or none. I also show that there is a natural link between the size of the government as a provider of public goods and the magnitude of transfers that the same government will implement.

*I am indebted to Gadi Barlevy, Kenneth Judd, Robert Lucas, Thomas Sargent, José Scheinkman, and Nancy Stokey for helpful comments. I also thank the Research Department of the Federal Reserve Bank of Minneapolis; part of this work was written while I was visiting their Institute for Empirical Macroeconomics and I benefited greatly from several conversations I had there. Any views of this paper are my own only. Address: Department of Economics, Northwestern University, 2003 Sheridan Road, Evanston, IL 60208; phone (847) 491-8233; email: m-bassetto@ nwu.edu. The views expressed herein are those of the author and not necessarily those of the Federal Reserve Bank of Minneapolis or the Federal Reserve System.
\end{abstract}




\title{
Political Economy of Taxation in an Overlapping-Generations Economy
}

\author{
Marco Bassetto* \\ This Version: December 1999 \\ First Draft: December 1997
}

\begin{abstract}
This paper builds a simple but complete model of a political system to analyze the effects of intergenerational conflicts on capital and labor income tax rates, transfers and government spending. I show how the different nature of tax liabilities for the young and the old can explain why the old receive large gross lump-sum transfers through social security, while the young receive little or none. I also show that there is a natural link between the size of the government as a provider of public goods and the magnitude of transfers that the same government will implement.
\end{abstract}

\section{Introduction}

The demographic changes that are taking place in the developed countries have led to a great interest in the economic implications of an aging population. Most of the interest has concentrated on the social-security systems in place in many countries; because of their pay-as-you-go structure, they may commit the governments to burdensome or even unsustainable transfers to future old generations.

The aim of this paper is to look at the fiscal effects of intergenerational conflicts from a somewhat broader perspective. Differences in age are one of the main sources of heterogeneity across individuals in modern societies: they account for a big component of the variability in asset holdings as well as in sources of income. As a consequence, the conflict between young and old is likely to arise on a broader set of fiscal instruments than the size of social-security transfers. In particular, the young and the old will have very different preferences regarding labor and capital income taxation, the former hitting mostly the young and the middle-aged, the latter hitting disproportionately the old.

This paper highlights thus two features of fiscal policies: first, they involve setting several policy parameters at the same time, so the political choice cannot be reduced to a mere unidimensional problem; second, government policies have dynamic implications, as current choices

\footnotetext{
${ }^{*}$ I am indebted to Gadi Barlevy, Kenneth Judd, Robert Lucas, Thomas Sargent, José Scheinkman and Nancy Stokey for helpful comments. I also thank the Research Department of the Federal Reserve Bank of Minneapolis; part of this work was written while I was visiting their Institute for Empirical Macroeconomics and I benefited greatly from several conversations I had there. Address: Department of Economics, Northwestern University, 2003 Sheridan Road, Evanston, IL 60208; phone (847) 491-8233; email m-bassetto@nwu.edu
} 
will influence the evolution of the economy and future policies, and this will be taken into account by rational, forward-looking agents. In this paper, I build a simple but complete model of a political system, that allows us to capture these two main features.

The economy I study is characterized by overlapping generations living two periods; the agents spend their first period working and accumulating capital that is used to provide for their old age. Besides their private consumption, both the young and the old value a public good; the presence of a political system is justified by the need to finance the provision of the public good. In order to finance the public good, the government can levy proportional taxes on capital and labor income, at different rates.

Most papers on the political economy of intergenerational transfers model the political process as a voting scheme. In this paper I model it as a sequential bargaining game: in each period the two generations alive bargain over the provision of the public good, the ways to finance it and possibly the size of (nonnegative) lump-sum transfers from the government to either generation. Voting schemes usually produce sharper predictions on the outcome of the political process, but they require assumptions on preferences that are usually met only when voting takes place on a single policy parameter. Bargaining is a better description of a political system in which decisions cannot be taken by small majorities, but must be supported by a large consensus, as it appears to be the case for most of the broad policy decisions I look at.

I show that in my setup we obtain a policy indeterminacy: ex post, a reduction of taxes on capital income and an increase in lump-sum transfers to the old are perfect substitutes. I show that the indeterminacy can be broken by considering "small" amounts of heterogeneity across old agents, and that the limiting policy that arises from such an argument entails a pay-as-you-go social-security system, in which positive lump-sum transfers are paid to the old and no transfers are paid to the young.

I also study the effects of a change in the population growth, both when it is anticipated and when it is not. Aging in the population leads to shrinking social-security transfers in the long run; however, for some parameter values the anticipation of aging in the future leads to a temporary increase in the size of the transfers.

Section 2 surveys previous literature on the issues that are addressed in the paper. Section 3 describes the main features of the economy I consider: the preferences, the technology and the political system. Section 4 discusses the equilibrium concept, derives the equations that characterize an equilibrium and studies some properties of the equilibria. Section 5 contains numerical results on the characteristics of the equilibria and on comparative statics exercises in a stationary environment. Section 6 studies the effects of anticipated and unanticipated changes in the demographics. Section 7 discusses how the results change if factor prices are endogenous. Section 8 concludes.

\section{The Literature}

A vast number of papers has addressed separately the issues of capital and labor income taxation and of social security.

On the structure of taxation, the literature has at first studied representative agent economies, such as in Chamley [4] and Chari, Christiano and Kehoe [5]. Chamley [4] shows that the optimal capital income tax rate converges to 0 in the long run in absence of uncertainty; when uncertainty is present, Chari, Christiano and Kehoe [5] show that the ex-ante tax rate should also converge 
to a small amount on average, whereas the taxation ex post is very volatile. Judd [12] has shown that the capital income tax rate will optimally converge to 0 even in a world of heterogeneous agents, if the economy reaches a steady state.

The previously mentioned papers on optimal taxation have considered the optimal policy for a "Ramsey" government, which can commit in advance to follow a given policy for the indefinite future.

Several authors have tried to explain differences across countries in the rate of capital income taxation by studying in more detail the political process that leads to the selection of a policy. This line of research is pursued by Alesina and Rodrik [1], by Persson and Tabellini [19] and by Krusell, Quadrini and Ríos-Rull [15] (KQR from now on). KQR devise a framework aimed at describing explicitly the political process by which the government decisions are taken. Their general framework is then applied to a specific dynamic "politico-economic equilibrium": in their model, the capital tax rate is set by sequential voting among agents whose capital endowment is different. These papers show that the political process that determines the selection of a policy may lead to inefficiently high tax rates on capital income. My analysis will retain the general framework of a dynamic politico-economic equilibrium, but will study a different source of heterogeneity among agents and a different political process: heterogeneity will come from differences in age rather than initial endowment, and the political process will be characterized by bargaining rather than voting.

The literature on social security systems has used even more often the tools of political economy, looking in particular at the conflict among different generations that arises from the transfers associated with pay-as-you-go systems.

Mulligan and Sala-i-Martin [17] consider the relationship between the political system and social security. Their aim is to explain the salient features of social security systems across the world. By looking at a pressure-group approach, they explain why the old seem to be very successful in attracting transfers and why most social security systems mandate retirement or implicitly tax labor supplied by the elderly at very high rates.

Cooley and Soares $[7,6]$ study how and whether a pay-as-you-go social security system can be sustained by "reputation", i.e., by an equilibrium where everybody expects the system to be in place for ever as long as it is not abolished, and everybody expects it never to be reinstated should it be abolished.

Lambertini and Azariadis [16] look at redistribution from the young skilled workers to all other groups in the economy, and show that some types of equilibria may lead to a coalition between the old and the young unskilled workers in favor of large transfers.

By focusing either on the structure of taxation or on specific aspects of distribution, all of the previously mentioned papers have not addressed the notion of "generational accounting" advocated by Kotlikoff [13]. Generational accounting measures how different generations contribute to the provision of the public goods by looking at all sources of tax revenues and all transfers at the same time. Kotlikoff argues that generational accounting is the appropriate measure for capturing how the fiscal policy affects different generations. A few papers have looked in more detail at how the current US fiscal policy and several alternative options treat different generations (e.g. Altig et al. [2]; Huang, İmrohoroğlu and Sargent [11]; De Nardi, İmrohoroğlu and Sargent [8]). These papers treat the fiscal policy as exogenous and explore the implications of different options.

The aim of my paper is to study how the political process determines which policy is actually implemented in this context. The additional complication of endogenizing the fiscal policy requires 
however a drastic simplification of the demographic structure of the population: instead of a long-lived overlapping-generations (OLG) model, I will study an economy where people live for 2 periods only. ${ }^{1}$

\section{The Model}

We consider an overlapping-generations economy where agents live for two periods. Each cohort is made of a continuum of agents; the size of the cohorts may be varying over time; the size of the cohort born at time $t$ is $n_{t}$ times the size of the cohort born at time $t-1$. There is no uncertainty in the economy, so there is perfect foresight about $n_{t}$. The economy starts at time 0 . There is a measure 1 of old agents alive in period 0 .

\subsection{Preferences}

In the economy there is one private good and one public good. All agents value both goods; the young also supply some labor that causes them disutility.

The preferences of an agent born at time $t$ are described by the following utility function:

$$
\log c_{t}^{y}-\gamma l_{t}+V\left(g_{t}\right)+\beta\left[\log c_{t+1}^{o}+\xi V\left(g_{t+1}\right)\right]
$$

where $c_{t}^{y}$ is consumption of the private good of a young agent at time $t, c_{t+1}^{o}$ is consumption of the private good of an old agent at time $t+1, l_{t}$ is the labor supply of a young agent at time $t$ and $g_{t}$ is the level of provision of the public good per capita at time $t$. $V$ is a continuously differentiable function, with $\lim _{g \rightarrow 0} V(g)=0$.

The preferences of the old agents alive in period 0 are just given by the component referring to the old, i.e.

$$
\log c_{0}^{o}+\xi V\left(g_{0}\right)
$$

While all people within a cohort are assumed to be the same for now, we will study equilibria that are robust to the introduction of small amounts of heterogeneity.

\subsection{Technology}

The private good is produced by a technology that uses capital supplied by the old and/or labor supplied by the young. $K_{t}$ units of capital per capita and $L_{t}$ units of labor per capita produce $F\left(K_{t}, L_{t}\right)$ units of the private good per capita. The technology displays constant returns to scale, is strictly increasing and weakly concave in each of the two inputs. In sections 5 and 6 , we assume a linear technology, in which factor prices are exogenously given:

$$
F\left(K_{t}, L_{t}\right)=R K_{t}+L_{t}
$$

\footnotetext{
${ }^{1}$ My setup is very similar to Renström [21]; the main difference between my paper and his lies in the political process. Renström [21] assumes that each tax rate and transfer is selected separately, so that voting takes place on a single issue at a time, treating all others as fixed. Each policy is voted upon one generation before it is to take effect; as a consequence, the current young have no say on the current policy and are hit by very high taxes on labor income (the labor-income tax rate will specifically be the one that maximizes tax revenues given the other tax rates and the transfers).
} 
In section 7, we consider a Cobb-Douglas production function:

$$
F\left(K_{t}, L_{t}\right)=A K_{t}^{\alpha} L_{t}^{1-\alpha}
$$

Given the length of the period I consider (1 generation), I assume that capital fully depreciates after each use. I assume that the technology is operated by competitive firms.

At any time $t$, the private good that is produced can either be consumed or saved as capital for next period.

The public good can be provided by converting immediately one unit of private good per capita into one unit of public good per capita. By its nature, the public good must be consumed by all the agents in the same quantity in any given period and cannot be thus provided by a competitive market.

Old agents at time 0 are born with an endowment of $k_{0}$ units of capital.

\subsection{Fiscal Constitution}

In order to provide the public good, the agents in the economy have devised a "government". In each period, the government raises revenues through taxes and uses the proceeds to purchase consumption goods to be converted into the public good and possibly to pay transfers to the young and/or old generation.

The government cannot use lump-sum taxes. It can only levy a proportional tax on labor and capital income; the tax rate on the two sources of income may be different. We assume the government can at most seize all of the revenues from labor income and all of the capital (both principal and interest), so the tax rates are constrained to be less than $100 \%$. In our calibrated examples this constraint will of course never be binding. While lump-sum taxes are excluded, the government can use (nonnegative) lump-sum transfers to any generation it wishes.

We assume for simplicity that the government is prevented from borrowing and/or saving: the government balance must hold in every period. ${ }^{2}$

A government policy is thus an infinite sequence of tax rates, transfers and levels of provision of the public good: $\left\{\tau_{t}^{l}, \tau_{t}^{k}, T_{t}^{y}, T_{t}^{o}, g_{t}\right\}_{t=0}^{\infty}$, where $\tau_{t}^{l}$ is the tax rate on labor income at time $t, \tau_{t}^{k}$ is the tax rate on capital at time $t, T_{t}^{y}$ and $T_{t}^{o}$ are the transfers to the young and to the old respectively, measured in units of consumption good per young (or old) agent. We will also refer to a one-period policy, which is an element of the sequence.

The previously mentioned constraints imply $\tau_{t}^{l} \leq 1, \tau_{t}^{k} \leq 1, T_{t}^{y} \geq 0, T_{t}^{o} \geq 0, g_{t} \geq 0$.

\subsection{Political System}

The previous subsection describes the instruments that are available to the government. We describe here how people interact to choose a particular policy.

At the beginning of each period, a person is selected at random to make a policy proposal. In order for her policy proposal to be implemented, a unanimous approval is required. If unanimity is not reached, there is a small probability $\epsilon$ that no further negotiations can take place in this

\footnotetext{
${ }^{2}$ Alternatively, we could assume that the government can issue debt but would always default on it ex post. This would happen if repayment of the debt was part of the bargaining ex post: the debt holders would have no leverage, because their debt would be just a worthless piece of paper under the threat-point policy of a government shutdown.
} 
period and hence a government "shutdown" happens: for one period, no taxes are levied, no transfers are carried out and the public good is not provided. With probability $1-\epsilon$, the game restarts with a new person being selected at random to make a policy proposal, and so on. I focus on Markov equilibria of this game, in which both the policy proposals and their acceptance only depend on the physical state variable, which is the current level of capital per old person, and do not depend on the past history of policies that have been implemented, proposed, accepted or rejected. Because the game is played under perfect information, a government shutdown never happens in equilibrium and the first proposal is always accepted.

Adapting an argument by Binmore, Rubinstein and Wolinsky [3], the outcome of the Markov equilibrium of the previous game can be approximated by the outcome of Nash bargaining when the probability $\epsilon$ goes to 0 . This also implies that the identity of the person that makes the first proposal becomes irrelevant in the limit. ${ }^{3}$

My choice of bargaining as a description of the political process stems from the observation that a large consensus is typically required to adopt laws affecting the general system of taxes and transfers, as well as the overall size of the government. In most democracies, minorities can (and sometimes do) exert significant veto power over laws connected to these broad choices, either within the parliament (e.g., through filibustering) or through alternative means (e.g., through strikes or by taking to the streets). Voting models do not capture this aspect well; they predict that a $51 \%$ majority could impose policies that are arbitrarily costly for the minority. While the unanimity that is required in my approach goes too far in the opposite direction, it is in my opinion a better approximation to the real political process.

Because bargaining allows different groups to express the magnitude of costs and benefits from different policies rather than just an order ranking, it also solves voting paradoxes that arise in a multidimensional environment such as the one I study. In my opinion, this solution is preferable to the alternative of voting on a single issue at a time, which rules out the trading of favors that is very commonly observed among politicians.

The threat of a complete government shutdown in case an agreement is not reached is a very extreme one. While many of the key insights of this paper are robust to the choice of a threat point, the numerical simulations depend on it. The analysis of alternative threat points is left to future research.

\subsection{Timing}

Within each period $t$, the timing of moves is as follows:

(i) a new generation of young people is born;

(ii) bargaining takes place to select the policy to be implemented in period $t$;

(iii) the firms hire workers and rent capital to produce;

\footnotetext{
${ }^{3}$ Binmore, Rubinstein and Wolinsky's results study bargaining between two people. In their environment, the Markov restriction is unnecessary; the only subgame perfect equilibrium satisfies it. With more than two people (or groups of people), there are many subgame perfect equilibria, only one of which is a Markov equilibrium. The convergence to the Nash bargaining outcome holds for the outcome of the Markov equilibrium, but not necessarily for the outcomes of other equilibria.
} 
(iv) the households receive the proceeds from the use of their factors of production, pay taxes due, receive transfers and consume; the young generation sets aside some of its proceeds as capital for the next period;

(v) the old generation dies, while the young generation ages and becomes old in the next period.

\section{Maximization and Equilibrium}

As in KQR, we will describe the equilibrium of our economy as a (dynamic) politico-economic equilibrium.

We first define a competitive equilibrium; a politico-economic equilibrium will be a particular competitive equilibrium.

\subsection{Competitive Equilibrium}

In a competitive equilibrium, each household maximizes over her lifetime consumption and leisure taking factor prices and the government policy as given. Each agent that is born at time $t \geq 0$ has thus the following budget constraints:

$$
\begin{gathered}
c_{t}^{y}+k_{t+1} \leq\left(1-\tau_{t}^{l}\right) w_{t} l_{t}+T_{t}^{y} \\
c_{t+1}^{o} \leq R_{t+1}\left(1-\tau_{t+1}^{k}\right) k_{t+1}+T_{t+1}^{o},
\end{gathered}
$$

where $w_{t}$ is the pre-tax wage rate at time $t$ and $R_{t+1}$ is the rental rate of capital at time $t+1$.

As already mentioned, for the old agents alive at time 0 we treat $k_{0}$ as an exogenously given

parameter. Note that $\tau_{t+1}^{k}$ as defined in the paper applies both to the principal and to interest earned on capital income. Furthermore, each period in the model lasts half of the adult life of a person, i.e. about 30 years. The appendix shows how to convert this tax rate into an annual tax rate levied only on the interest, under the assumption that the tax rate and the interest rate are constant within the 30-year period. We will use the annualized tax rate for displaying all of the numerical results. We will denote the annualized tax rate as $\hat{\tau}_{t+1}^{k}$.

The optimal choices of an agent born at time $t \geq 0$ are given by

$$
\begin{gathered}
l_{t}=\max \left\{\frac{1+\beta}{\gamma}-\frac{T_{t}^{y}+\frac{T_{t+1}^{o}}{\beta R_{t+1}\left(1-\tau_{t+1}^{k}\right)}}{w_{t}\left(1-\tau_{t}^{l}\right)}, 0\right\} \\
k_{t+1}=\max \left\{\frac{\beta w_{t}\left(1-\tau_{t}^{l}\right)}{\gamma}-\frac{T_{t+1}^{o}}{R_{t+1}\left(1-\tau_{t+1}^{k}\right)}, \frac{\beta T_{t}^{y}}{1+\beta}-\frac{T_{t+1}^{o}}{(1+\beta) R_{t+1}\left(1-\tau_{t+1}^{k}\right)}\right\} \\
c_{t}^{y}=w_{t}\left(1-\tau_{t}^{l}\right) l_{t}-k_{t+1}+T_{t}^{y} \\
c_{t+1}^{o}=R_{t+1}\left(1-\tau_{t+1}^{k}\right) k_{t+1}+T_{t+1}^{o}
\end{gathered}
$$


Notice that no equilibrium will be possible if people expect $\tau_{t+1}^{k}=1$ : there would be an incentive to borrow indefinitely. We could solve this problem by assuming that no tax credit is given to net debtors, but this would be irrelevant, for we are interested in economies in which capital is always strictly positive and $\tau_{t}^{k}<1$ at any date $t$. Because a negative labor supply is impossible, setting $\tau_{t}^{l}$ to 1 implies that nobody will work; again, we are interested in economies where this does not happen and $\tau_{t}^{l}<1$ at any date $t$.

For old agents at time 0 , there is no choice given the government policy: their consumption is given by (10), with $k_{0}$ given.

In a competitive equilibrium, each firm maximizes its profits taking factor prices as given. The firms' problem is thus

$$
\max _{K_{t}, L_{t}} F\left(K_{t}, L_{t}\right)-w_{t} L_{t}-R_{t} K_{t}
$$

s.t. $K_{t} \geq 0, L_{t} \geq 0$.

A competitive equilibrium requires thus

$$
R_{t} \geq F_{K}\left(K_{t}, L_{t}\right), K_{t} \geq 0,\left(R_{t}-F_{K}\left(K_{t}, L_{t}\right)\right) K_{t}=0
$$

and

$$
w_{t} \geq F_{L}\left(K_{t}, L_{t}\right), L_{t} \geq 0,\left(w_{t}-F_{L}\left(K_{t}, L_{t}\right)\right) L_{t}=0
$$

While we include the nonnegativity constraints in our definition of an equilibrium, in practice we will calibrate the model so that they are never binding.

Definition 1 (competitive equilibrium) A competitive equilibrium is defined as an allocation $\left\{\left(c_{t}^{y}, c_{t}^{o}, l_{t}, k_{t}, L_{t}, K_{t}\right)\right\}_{t=0}^{\infty}$, factor prices $\left\{\left(R_{t}, w_{t}\right)\right\}_{t=0}^{\infty}$ and a policy $\left\{\left(\tau_{t}^{l}, \tau_{t}^{k}, T_{t}^{y}, T_{t}^{o}, g_{t}\right)\right\}_{t=0}^{\infty}$ such that:

(i) given the policy and the factor prices, the allocation solves the maximization problem of each household, i.e. it satisfies equations (9), (10), (7) and (8) for each $t \geq 0$ and (10) for $t+1=0$ as well;

(ii) given the allocation, the factor prices are consistent with the firms' profit maximization, i.e., equations (12) and (13) are satisfied for each $t \geq 0$;

(iii) the market for the private good clears in each period $t \geq 0$, i.e.

$$
\frac{n_{t} c_{t}^{y}+c_{t}^{o}+n_{t} k_{t+1}}{1+n_{t}}+g_{t}=F\left(K_{t}, L_{t}\right)
$$

(iv) the markets for production inputs clear in each period $t \geq 0$, i.e.,

$$
K_{t}=\frac{k_{t}}{1+n_{t}}
$$

and

$$
L_{t}=\frac{n_{t} l_{t}}{1+n_{t}} .
$$


The previous requirements imply that the government budget constraint

$$
g_{t}=\frac{n_{t} w_{t} \tau_{t}^{l} l_{t}+\tau_{t}^{k} R_{t} k_{t}-n_{t} T_{t}^{y}-T_{t}^{o}}{1+n_{t}}
$$

is satisfied as well.

(v) $k_{0}$ is given by the initial condition (exogenous).

The definition of a competitive equilibrium involves sequences of variables from period 0 to the infinite future. It is sometimes useful to look at time- $t$ choices by themselves and study under what conditions they could be part of a competitive equilibrium. At time $t$, each old household inherits a level of capital $k_{t}$ from period $t-1$.

In order to solve their maximization problem at time $t$, the young households need to know the policy and factor prices at times $t$ and $t+1$, i.e. $\theta_{t} \equiv\left(\tau_{t}^{l}, \tau_{t}^{k}, T_{t}^{y}, T_{t}^{o}, g_{t}, R_{t}, w_{t}\right)$ and (a subset of the elements of) $\theta_{t+1}$. The old households only need to know $\theta_{t}$, as they will consume all of their savings in period $t$ and die thereafter. As the old households, the firms only need information about $\theta_{t}$ for their time- $t$ decisions: this is because their maximization problem is static.

Definition 2 (temporary competitive equilibrium) A temporary competitive equilibrium from an initial level of capital $k_{t}$ is a time- $t$ allocation $\left(c_{t}^{y}, l_{t}, k_{t+1}, c_{t}^{o}, L_{t}, K_{t}\right)$ and time- $t$ and $t+1$ policies and factor prices $\left(\theta_{t}, \theta_{t+1}\right)$ such that:

(i) given $\theta_{t}$ and $\theta_{t+1},\left(c_{t}^{y}, l_{t}, k_{t+1}\right)$ solves the maximization of young households at time $t$, i.e. it satisfies equations (9), (7) and (8);

(ii) given $k_{t}$ and $\theta_{t}$, the consumption of the old is given by equation (10) evaluated at time $t$, i.e. $c_{t}^{o}=R_{t} k_{t}+T_{t}^{o}$.

(iii) given the allocation, the factor prices are consistent with the firms' profit maximization at time $t$, i.e., equations (12) and (13) are satisfied;

(iv) the market for the private good clears in period $t$, i.e. equation (14) holds;

(v) the markets for production inputs clear in period $t$, i.e. equations (15) and (16) hold.

The following proposition highlights that a competitive equilibrium can be viewed as a sequence of temporary equilibria.

Proposition 1 Let $\left\{\left(c_{t}^{y}, c_{t}^{o}, l_{t}, k_{t}, L_{t}, K_{t}\right)\right\}_{t=0}^{\infty}$ and $\left\{\theta_{t}\right\}_{t=0}^{\infty}$ be a competitive equilibrium. Then, for each $t \geq 0,\left(c_{t}^{y}, c_{t}^{o}, l_{t}, k_{t+1}, L_{t}, K_{t}\right)$ and $\left(\theta_{t}, \theta_{t+1}\right)$ are a temporary competitive equilibrium from $k_{t}$. Conversely, let $\left\{\left(c_{t}^{y}, c_{t}^{o}, l_{t}, k_{t}, L_{t}, K_{t}\right)\right\}_{t=0}^{\infty}$ and $\left\{\theta_{t}\right\}_{t=0}^{\infty}$ be such that $\left(c_{t}^{y}, c_{t}^{o}, l_{t}, k_{t+1}, L_{t}, K_{t}\right)$ and $\left(\theta_{t}, \theta_{t+1}\right)$ are a temporary competitive equilibrium from $k_{t}$ for any $t \geq 0$. Then the sequences $\left\{\left(c_{t}^{y}, c_{t}^{o}, l_{t}, k_{t}, L_{t}, K_{t}\right)\right\}_{t=0}^{\infty}$ and $\left\{\theta_{t}\right\}_{t=0}^{\infty}$ are a competitive equilibrium.

Proof. By comparing definitions 1 and 2, it follows immediately that the same equations hold in the two cases of the theorem. ${ }^{4}$

\footnotetext{
${ }^{4}$ The proof of proposition 1 is trivial because of our overlapping-generations structure and the balanced-budget requirement imposed on the government. Because of these assumptions, the transversality conditions are automatically satisfied. For a version of this proposition in an environment with infinitely-lived agents, see Phelan and Stacchetti [20].
} 


\subsection{Politico-Economic Equilibrium}

We now turn our attention to the determination of the government policy.

We already described how the political process takes place in each period. To characterize the politico-economic equilibrium, we need however to consider the dynamic aspects of the bargaining game that takes place in the economy.

As in KQR, we look for "Markov equilibria", i.e. equilibria in which the outcome of bargaining and future factor prices are functions only of the capital level in the economy and of calendar time. Capital is the only physical state variable in the economy, and allowing for time variation is necessary to study environments in which there is a demographic transition. The assumption we make rules out equilibria in which the current outcome of the bargaining depends directly on the past outcomes, as in "reputation" equilibria. This seems particularly acceptable in our setup, where periods are very long (half of the adult life of a person) and bargaining takes place among different agents at each point in time ${ }^{5}$.

The dynamic aspect of bargaining stems from the fact that the current policy affects capital accumulation, thereby changing the strategic position of the currently young agents in the next period. When bargaining over the current policy, young agents take into account its effects on the outcome of bargaining in the next period.

Let us thus assume that the agents at time $t$ expect the government policy next period to be characterized by

$$
\left(\tau_{t+1}^{l}, \tau_{t+1}^{k}, T_{t+1}^{y}, T_{t+1}^{o}, g_{t+1}\right)=\left(\pi_{t+1}^{l}\left(k_{t+1}\right), \pi_{t+1}^{k}\left(k_{t+1}\right), \pi_{t+1}^{y}\left(k_{t+1}\right), \pi_{t+1}^{o}\left(k_{t+1}\right), \pi_{t+1}^{g}\left(k_{t+1}\right)\right)
$$

and the future factor prices to be

$$
\left(R_{t+1}, w_{t+1}\right)=\left(\pi_{t+1}^{R}\left(k_{t+1}\right), \pi_{t+1}^{w}\left(k_{t+1}\right)\right)
$$

for some functions $\left(\pi_{t+1}^{l}, \pi_{t+1}^{k}, \pi_{t+1}^{y}, \pi_{t+1}^{o}, \pi_{t+1}^{g}, \pi_{t+1}^{R}, \pi_{t+1}^{w}\right) \equiv \pi_{t+1}$. Let the level of capital owned by each old household at time $t$ be $k_{t}$. We can find a set of policies $\theta_{t}$ such that there exists a time- $t$ allocation $\left(c_{t}^{y}, c_{t}^{o}, l_{t}, k_{t+1}, L_{t}, K_{t}\right)$ that is a temporary competitive equilibrium with $\left(\theta_{t}, \pi_{t+1}\left(k_{t+1}\right)\right)$. Let $\mathcal{P}\left(\pi_{t+1}, k_{t}\right)$ be the set of such policies. The bargaining solution is well-defined when $\mathcal{P}\left(\pi_{t+1}, k_{t}\right)$ is nonempty and contains the threat-point policy, i.e., it contains at least a vector of the form $\left(\mathbf{0}, R_{t}, w_{t}\right)$ for some $R_{t}$ and $w_{t}$. Notice that, given a policy $\left(\tau_{t}^{l}, \tau_{t}^{k}, T_{t+1}^{y}, T_{t+1}^{o}, g_{t}\right)$, there might be more than one choice of $\left(c_{t}^{y}, c_{t}^{o}, l_{t}, k_{t+1}, L_{t}, K_{t}\right)$ and $\theta_{t+1}=\pi_{t+1}\left(k_{t+1}\right)$ that form a temporary competitive equilibrium from $k_{t}$. Therefore, for a rule $\pi_{t+1}$, some choices of a time- $t$ government policy may lead to multiple equilibria. However, the following proposition holds.

Proposition 2 Given a rule $\pi_{t+1}$, let $\left(k_{t+1}, \tau_{t}^{k}, T_{t}^{y}, T_{t}^{o}\right)$ be a vector that satisfies

$$
k_{t+1} \geq \frac{\beta T_{t}^{y}}{1+\beta}-\frac{\pi_{t+1}^{o}\left(k_{t+1}\right)}{(1+\beta) \pi_{t+1}^{R}\left(k_{t+1}\right)\left(1-\pi_{t+1}^{k}\left(k_{t+1}\right)\right)} .
$$

\footnotetext{
${ }^{5}$ Kotlikoff, Persson and Svensson [14], however, consider a model where each generation can improve its utility by selling to the next one a "social asset" that plays the same role as reputation.
} 
If (20) is a strict inequality, let the vector satisfy also

$$
\begin{aligned}
F\left[\frac{k_{t}}{1+n_{t}},\right. & \left.\frac{n_{t}}{1+n_{t}}\left(\frac{1+\beta}{\gamma}-\frac{T_{t}^{y} \beta \pi_{t+1}^{R}\left(k_{t+1}\right)\left(1-\pi_{t+1}^{k}\left(k_{t+1}\right)\right)+\pi_{t+1}^{o}\left(k_{t+1}\right)}{\gamma\left[\pi_{t+1}^{R}\left(k_{t+1}\right)\left(1-\pi_{t+1}^{k}\left(k_{t+1}\right)\right) k_{t+1}+\pi_{t+1}^{o}\left(k_{t+1}\right)\right]}\right)\right] \\
- & \frac{n_{t}(1+\beta) k_{t+1}}{\beta\left(1+n_{t}\right)}-\frac{n_{t} \pi_{t+1}^{o}\left(k_{t+1}\right)}{\pi_{t+1}^{R}\left(k_{t+1}\right)\left(1-\pi_{t+1}^{k}\left(k_{t+1}\right)\right)\left(1+n_{t}\right)}-\frac{T_{t}^{o}}{1+n_{t}}-\frac{\left(1-\tau_{t}^{k}\right) k_{t}}{1+n_{t}} \\
& \cdot F_{K}\left[\frac{k_{t}}{1+n_{t}}, \frac{n_{t}}{1+n_{t}}\left(\frac{1+\beta}{\gamma}-\frac{T_{t}^{y} \beta \pi_{t+1}^{R}\left(k_{t+1}\right)\left(1-\pi_{t+1}^{k}\left(k_{t+1}\right)\right)+\pi_{t+1}^{o}\left(k_{t+1}\right)}{\gamma\left[\pi_{t+1}^{R}\left(k_{t+1}\right)\left(1-\pi_{t+1}^{k}\left(k_{t+1}\right)\right) k_{t+1}+\pi_{t+1}^{o}\left(k_{t+1}\right)\right]}\right)\right] \geq 0
\end{aligned}
$$

If (20) holds with equality, let $\left(k_{t+1}, \tau_{t}^{k}, T_{t}^{y}, T_{t}^{o}\right)$ satisfy instead

$$
F\left[\frac{k_{t}}{1+n_{t}}, 0\right]-\frac{T_{t}^{y} n_{t}}{1+n_{t}}-\frac{T_{t}^{o}}{1+n_{t}}-\frac{\left(1-\tau_{t}^{k}\right) k_{t}}{1+n_{t}} F_{K}\left[\frac{k_{t}}{1+n_{t}}, 0\right] \geq 0 .
$$

Then $\left(k_{t+1}, \tau_{t}^{k}, T_{t}^{y}, T_{t}^{o}\right)$ is part of a temporary competitive equilibrium $\left(c_{t}^{y}, c_{t}^{o}, l_{t}, k_{t+1}, L_{t}, K_{t}\right), \theta_{t}=$ $\left(\tau_{t}^{l}, \tau_{t}^{k}, T_{t}^{y}, T_{t}^{o}, g_{t}, R_{t}, w_{t}\right)$ and $\theta_{t+1}$ such that $\theta_{t+1}=\pi_{t+1}\left(k_{t+1}\right)$. Furthermore, this equilibrium is uniquely determined by $\left(c_{t}^{y}, c_{t}^{o}, l_{t}, k_{t+1}, L_{t}, K_{t}\right)$, except possibly for factor prices and tax rates that refer to factors in 0 supply.

Proof. See appendix A.

Proposition 3 Given a rule $\pi_{t+1}$, let $\left(k_{t+1}, \tau_{t}^{k}, T_{t}^{y}, T_{t}^{o}\right)$ be a vector such that:

(i) either (20) is violated;

(ii) or (20) holds as a strict inequality but (21) is violated;

(iii) or (20) holds as an equality but (22) is violated.

Then the vector $\left(k_{t+1}, \tau_{t}^{k}, T_{t}^{y}, T_{t}^{o}\right)$ is not part of any temporary competitive equilibrium in which $\theta_{t+1}=\pi_{t+1}\left(k_{t+1}\right)$.

Proof. See appendix A.

In all of our calibrated examples, both the labor supply and capital will be strictly positive, so that the proposition 2 will imply uniqueness of all the elements of a temporary competitive equilibrium.

For given $\pi_{t+1}$ and $k_{t}$, propositions 2 and 3 allow us to express any temporary competitive equilibrium as a function of $\left(k_{t+1}, \tau_{t}^{k}, T_{t}^{y}, T_{t}^{o}\right)$. We can thus think that the young and the old bargain at time $t$ directly over $\left(k_{t+1}, \tau_{t}^{k}, T_{t}^{y}, T_{t}^{o}\right)$ rather than over a time- $t$ policy $\left(\tau_{t}^{l}, \tau_{t}^{k}, T_{t}^{y}, T_{t}^{o}, g_{t}\right)$; the policy that supports $\left(k_{t+1}, \tau_{t}^{k}, T_{t}^{y}, T_{t}^{o}\right)$ can then be deduced from the proof of proposition 2 . Notice that the direct bargaining takes place over a 4-dimensional vector, whereas the policy is 5-dimensional: this is not surprising, because the government can really control independently only 4 out of 5 policy instruments, the last being set by its budget constraint. Replacing one policy instrument with $k_{t+1}$ requires however a more subtle assumption: that the government has the ability to steer the economy to its preferred equilibrium when a given policy vector is consistent with multiple values of $k_{t+1}$, and hence with multiple temporary competitive equilibria. We will maintain this assumption. 
We can now compute the utility that the agents receive in a temporary competitive equilibrium characterized by $\left(k_{t+1}, \tau_{t}^{k}, T_{t}^{y}, T_{t}^{o}\right)$, a rule $\pi_{t+1}$ and an initial capital level $k_{t}$; for the old agents at time $t$, we only look at utility in the second period of their life. We define $U^{y}\left(k_{t}, k_{t+1}, \tau_{t}^{k}, T_{t}^{y}, T_{t}^{o}, \pi_{t+1}\left(k_{t+1}\right)\right)$ to be the utility the young receive in such an equilibrium. Analogously, the utility of the old is given by $U^{o}\left(k_{t}, k_{t+1}, \tau_{t}^{k}, T_{t}^{y}, T_{t}^{o}, \pi_{t+1}\left(k_{t+1}\right)\right) .^{6}$

Definition 3 (politico-economic equilibrium) A politico-economic equilibrium is a competitive equilibrium and rules $\left\{\pi_{t}\right\}_{t=0}^{\infty}$ such that

(i) $\forall t \geq 0,\left(\tau_{t}^{l}, \tau_{t}^{k}, T_{t}^{y}, T_{t}^{o}, g_{t}, R_{t}, w_{t}\right)=\left(\pi_{t}^{l}\left(k_{t}\right), \pi_{t}^{k}\left(k_{t}\right), \pi_{t}^{y}\left(k_{t}\right), \pi_{t}^{o}\left(k_{t}\right), \pi_{t}^{g}\left(k_{t}\right), \pi_{t}^{R}\left(k_{t}\right), \pi_{t}^{w}\left(k_{t}\right)\right)$.

(ii) given any value $\hat{k}_{t},\left(\pi_{t}^{l}\left(\hat{k}_{t}\right), \pi_{t}^{k}\left(\hat{k}_{t}\right), \pi_{t}^{y}\left(\hat{k}_{t}\right), \pi_{t}^{o}\left(\hat{k}_{t}\right), \pi_{t}^{g}\left(\hat{k}_{t}\right), \pi_{t}^{R}\left(\hat{k}_{t}\right), \pi_{t}^{w}\left(\hat{k}_{t}\right)\right)$ represents the government policy and factor prices in the temporary competitive equilibrium that solves

$$
\begin{aligned}
\max _{\left(\hat{k}_{t+1}, \hat{\tau}_{t}^{k}, \hat{T}_{t}^{y}, \hat{T}_{t}^{o}\right)} & {\left[U^{y}\left(\hat{k}_{t}, \hat{k}_{t+1}, \hat{\tau}_{t}^{k}, \hat{T}_{t}^{y}, \hat{T}_{t}^{o}, \pi_{t+1}\left(\hat{k}_{t+1}\right)\right)-U^{y}\left(\hat{k}_{t}, k_{t+1}^{*}, \mathbf{0}, \pi_{t+1}\left(k_{t+1}^{*}\right)\right)\right]^{n_{t}} } \\
\cdot & {\left[U^{o}\left(\hat{k}_{t}, \hat{k}_{t+1}, \hat{\tau}_{t}^{k}, \hat{T}_{t}^{y}, \hat{T}_{t}^{o}, \pi_{t+1}\left(\hat{k}_{t+1}\right)\right)-U^{o}\left(\hat{k}_{t}, k_{t+1}^{*}, \mathbf{0}, \pi_{t+1}\left(k_{t+1}^{*}\right)\right)\right] }
\end{aligned}
$$

subject to nonnegativity of the surplus of both the young and the old, where $k_{t+1}^{*}$ is any capital level such that, given $\pi_{t+1}$ and $\hat{k}_{t},\left(k_{t+1}^{*}, 0\right)$ is part of a temporary competitive equilibrium in which $\tau_{t}^{l}=0$ and $g_{t}=0$; this is an equilibrium in which the government implements the threat-point policy at time $t$. The existence of such an equilibrium is equivalent to the assumption that $\mathcal{P}\left(\pi_{t+1}, \hat{k}_{t}\right)$ contains the threat-point policy.

The definition of a politico-economic equilibrium has the usual fixed point structure induced by rational expectations: it is a competitive equilibrium in which the functions that describe the outcome of bargaining coincide with the ones that the agent anticipate while bargaining in previous periods. A politico-economic equilibrium requires optimality of the current policy choice with respect to one-period deviations: equation (23) assumes that the equilibrium policy rule $\pi_{t+1}$ will be followed in period $t+1$ even after a deviation in period $t .^{7}$

In order to be able to compute politico-economic equilibria, we will restrict our attention to "eventually stationary" equilibria.

Definition 4 (eventually stationary politico-economic equilibrium, ESPEE) We call a politico-economic equilibrium eventually stationary (ESPEE) if $\pi_{t+j}=\pi_{t} \forall j, \forall t \geq T$, i.e., if it is an equilibrium in which the policy and factor-price rules reach a steady state after $T$ periods. In order to find ESPEEs, we will require the population growth parameter $n_{t}$ to be eventually constant.

The following proposition shows that a severe indeterminacy arises in computing the bargaining solution in (23).

\footnotetext{
${ }^{6}$ Notice that $\pi_{t+1}\left(k_{t+1}\right)$ plays a role in determining the utility of the old at time $t$, as well as that of the young: this is because the rental rate of capital $R_{t}$ may depend on the labor supply of the young. When the technology is linear and $R_{t}$ is fixed, $\pi_{t+1}\left(k_{t+1}\right)$ does not affect the old directly.

${ }^{7}$ This is a sufficient requirement for subgame perfection because the game we consider is continuous at infinity.
} 
Proposition 4 (Indeterminacy of the optimal policy) Let the vector $\left(k_{t+1}, \tau_{t}^{k}, T_{t}^{y}, T_{t}^{o}\right)$ determine a temporary competitive equilibrium from $k_{t}$ given a rule $\pi_{t+1}$. Let $R_{t}$ be the rental rate of capital in this equilibrium. Then any vector $\left(\hat{k}_{t+1}, \hat{\tau}_{t}^{k}, \hat{T}_{t}^{y}, \hat{T}_{t}^{o}\right)$ such that $\hat{k}_{t+1}=k_{t+1}, \hat{T}_{t}^{y}=T_{t}^{y}$ and

$$
\left(1-\hat{\tau}_{t}^{k}\right) R_{t} k_{t}+\hat{T}_{t}^{o}=\left(1-\tau_{t}^{k}\right) R_{t} k_{t}+T_{t}^{o}
$$

determines a temporary competitive equilibrium in which the utility of each generation is the same as the one in the equilibrium determined by $\left(k_{t+1}, \tau_{t}^{k}, T_{t}^{y}, T_{t}^{o}\right)$. Consequently, if a solution to the maximization problem (23) exists, then there exists a continuum of policies attaining the maximum.

Proof. See appendix A.

Proposition 4 comes simply from the fact that capital income taxation is lump sum ex post: an increase in the tax on capital income is perfect substitute of a decrease in the lump-sum transfers to the old.

\subsection{Breaking the Indeterminacy of the Optimal Policy}

While ex-post changing taxation on capital income or the lump-sum transfer to the old lead to the same outcome, their anticipated effect is of course very different. We therefore need to break the indeterminacy to be able to describe the policy that will be implemented in our economy.

We will break the indeterminacy by using a limiting argument. Note that the capital income tax rate and the lump-sum transfer would have a different impact on agents endowed with different amounts of capital. We will thus study how the capital income tax rate and the lump-sum transfer are determined when there is heterogeneity in the capital holdings of the old, and consider the limiting values for these variables when the difference in the capital holdings converges to 0 .

The appendix contains the theorem and proofs for general distributions of capital holdings. Since the results are the same, we assume here that the old agents are divided in two groups: a proportion $\alpha$ of the agents is endowed with $k_{t}+(1-\alpha) \hat{k}$ units of capital, and the remaining $1-\alpha$ have $k_{t}-\alpha \hat{k}$ units of capital. Note that, on average, each old agent has still $k_{t}$ units of capital. Because of this, equation (17) still holds and it is still true that the young agents in the economy are indifferent among different choices of $\tau_{t}^{k}$ and $T_{t}^{o}$ that leave average consumption of the old (i.e. $\left.\left(1-\tau_{t}^{k}\right) R_{t} k_{t}+T_{t}^{o}\right)$ unchanged. We can thus split the bargaining problem in two stages: in the first stage, the young and the old bargain together and leave the choice of $\tau_{t}^{k}$ and $T_{t}^{o}$ indeterminate, subject to equation (24). In the second stage, the old bargain over $\tau_{t}^{k}$ and $T_{t}^{o}$ subject to (24). We call this second stage conditional bargaining, as the average consumption level $c_{t}^{o}=\left(1-\tau_{t}^{k}\right) R_{t} k_{t}+T_{t}^{o}$ and the provision of the public good $g_{t}$ are treated as fixed, assuming that agreement prevails and the threat point is avoided.

Definition 5 (Robustness to small heterogeneity) An ESPEE is robust to small heterogeneity if $\left(\tau_{t}^{k}, T_{t}^{o}\right)$ are the limit of the policy chosen by conditional bargaining among the old given their average consumption level $c_{t}^{o}$ and the level of provision of the public good $g_{t}$ when $\hat{k} \rightarrow 0$.

From now on, we will only look at equilibria that are robust to small heterogeneity. 
Proposition 5 Assume an ESPEE is such that $k_{t}>0 \forall t$ and such that the utility of either generation at any point in time is strictly above its threat point. ${ }^{8}$ Then the ESPEE is robust to small heterogeneity if and only if

$$
\left\{\begin{array}{l}
1-\tau_{t}^{k}=\frac{c_{t}^{o}}{R_{t} k_{t}\left(1+D U_{t}\right)} \\
T_{t}^{o}=\frac{D U_{t}}{1+D U_{t}} c_{t}^{o}
\end{array} \quad \forall t \geq 0,\right.
$$

where $D U_{t}$ is the difference in utility between what an old agent gets and her threat point, evaluated when there is no heterogeneity $(\hat{k}=0)$, i.e.,

$$
D U_{t} \equiv \log c_{t}^{o}+\xi V\left(g_{t}\right)-\log \left(R_{t}^{*} k_{t}\right) .
$$

$R_{t}^{*}$ is the rental rate of capital in the temporary competitive equilibrium associated with the threatpoint policy at time $t$ and a time-t +1 policy determined according to the rule $\pi_{t+1} \cdot R_{t}^{*}$ is thus the rental rate of capital that the old expect to obtain if bargaining fails in the current period and the threat-point policy is implemented.

Proof. See appendix A.

Corollary 1 Whenever the outcome of the bargaining is such that the utility of the agents is above the threat point, $T_{t}^{o}$ is strictly positive in an ESPEE robust to small heterogeneity.

Proof. Immediate from (25).

Corollary 1 states that in any "interesting" equilibrium, i.e. when there is a role for a government in improving the utility of the agents, the outcome of the bargaining process will imply that some lump-sum transfers ("pensions") will be paid to the old. It is noteworthy that pensions are paid out, even when the resources for these pensions come, at least in part, from taxation on capital income. This feature of the equilibrium points to a major inefficiency arising from timeinconsistency: a policy of reducing both lump-sum transfers to the old and taxation on capital income would lead to a reduction in the distortions ex-ante, when the agents anticipate it and invest accordingly.

\section{$5 \quad$ Equilibria in a Stationary Environment}

In this section and the following, we assume a linear technology given by (3), so factor prices are exogenously given.

In this section we study the characteristics of the politico-economic equilibrium in a stationary environment, where population growth is constant over time at a rate $n$. We will look at stationary equilibria, for which the rule $\pi_{t}$ is invariant over time.

The algorithm that was used to solve for the equilibrium is described in the appendix.

Table 1 provides the baseline values I chose for the parameters of the economy in the computations. $\gamma=1$ is just a normalization connected with the measurement unit for the labor supply. ${ }^{9}$

\footnotetext{
${ }^{8}$ It is easy to show that, when $k_{t}>0$, if the utility of the young people is strictly above their threat point at any point in time, then so is the utility of the old, and vice versa.

${ }^{9}$ Note that a change in the measurement unit for the labor supply requires changing not only $\gamma$, but $\phi$ as well.
} 


$\begin{array}{cc}\gamma & 1 \\ \beta & 0.2181 \approx 0.95^{30} \\ \xi & 0.5131 \\ R & 5.7435 \approx 1.06^{30} \\ V\left(g_{t}\right) & \phi \frac{g^{1-\sigma}}{1-\sigma} \\ \phi & 0.497 \\ \sigma & 0.6977 \\ n & 2 \approx 1.0234^{30}\end{array}$

Table 1: Baseline parameters

I calibrated the real interest rate to be an annual $6 \%$; in our economy there is no risk, so I chose the return on capital to lie between the risk-free rate and the rate of return on stocks we observe in the data. The population growth I selected is somewhat high by historical standards; on the other hand, this growth rate delivers a fraction of elderly of $33 \%$, which is already quite high. Future research will consider an economy where people live for more than 2 periods, and will therefore relieve the tension between a reasonable fraction of elderly and a realistic value for the growth rate in the population. The remaining parameters were calibrated to match the tax rates on labor and capital, as well as social-security benefits and of government spending as a fraction of GNP. The steady-state tax rate on labor is assumed to be $27 \%$, the tax rate on capital is $20 \%,{ }^{10}$ social-security transfers are about $9 \%$ of $\mathrm{GNP}^{11}$ and government spending is about $18 \%$ of GNP. ${ }^{12}$

These values imply a substantial transfer of resources from the young to the old; in our model, such a large transfer can only be explained if the young value the provision of the public good substantially more than the old, i.e., if $\beta>\hat{\beta}$. Most of the results on comparative statics and on the dynamics of the system do not depend on this parameterization; when they do, I will mention explicitly the differences.

Figure 1 shows the stationary policy rule as a function of the capital held by the old. A variation in the initial capital level held by the old has two main effects:

\footnotetext{
${ }^{10}$ This model assumes proportional taxation both of capital and labor income; as a consequence, the tax rate is at the same time the average and the marginal rate. Computing an appropriate number for the tax rates on capital is particularly complicated because different sources of capital income are taxed at very different rates; furthermore, individual retirement accounts and pension plans imply that some funds obtain preferential tax treatment even within the same category of investments. Fullerton and Rogers [9] estimate an overall marginal tax rate of capital of $33 \%$ in 1984 in the U.S.; on the other hand, Gordon and Slemrod [10] find that in the same period the average tax on capital is slightly negative, although they suggest that the 1986 tax reform and the reduction in the inflation rate since the early 80 's led to a reduction in the arbitrage opportunities and an hence to an increase in average taxes on capital. Our value of $20 \%$ is somewhere in between the two estimates that were obtained. The results would be similar if we chose to calibrate the model to obtain a tax rate on capital of $33 \%$. It is instead impossible to obtain in this model a tax rate on capital close to 0 at the same time as significant social-security payments: as highlighted in the text, the combination of a tax on capital and lump-sum payments to the old implement an intragenerational transfer within the old cohort that is one of the key features of this paper. A similar transfer could arise in an environment in which capital taxes are nonlinear, with low average rates and higher marginal rates. An exploration of how this would interact with the transfers depending on the form a progressive tax system takes is beyond the scope of this paper.

${ }^{11}$ This number corresponds roughly to the size of Income Security, Social Security and Medicare transfers.

${ }^{12}$ This is calibrated to total government consumption expenditures and gross investment.
} 
(i) The more capital the old agents have, the higher is their threat point; this tends to strengthen the bargaining position of the old.

(ii) The more capital the old agents have, the more private good they consume for a given contribution to the provision of the public good; as a consequence, for a given contribution, the more capital the old agents have, the more they value the public good compared to the private good. This second effect weakens their bargaining position.

For the parameterization shown, the second effect is always prevalent. Due to this effect, the provision of the public good increases with the level of initial capital. Furthermore, the "richer" among the old are weakened by having more capital and hence larger pensions are paid when capital is more abundant; at the same time, the tax rate on capital income is increased. The net contribution to government spending by the old, which is depicted in figure 2, increases when the old have a larger capital. Similarly, for this parameterization the labor income tax rate decreases in the amount of capital, as the young are more successful in bargaining to offer the old a smaller transfer; this result is however dependent on the specific parameterization: for other parameter values, the tax on labor income is more or less constant or even slightly increasing in the amount of capital held by the old, as in that case the effect described in (i) is more important.

While in equilibrium the old receive lump-sum transfers, in my numerical simulations this never happens for the young. This is because bargaining over the policy happens before the production stage, and hence the young agents take into account the distortions stemming from the labor income tax when bargaining. For this reason, they would prefer a decrease in the tax rate on labor income to a lump-sum transfer of the same amount.

Figure 3 studies the behavior over time of capital in the economy. As we see from the picture, the initial level of capital has only a modest impact on the future capital level; this is not surprising, as we are considering very long periods. The behavior of investment in future capital mirrors the tax rate on labor income: for our parameterization, it is increasing in the amount of capital held by the old, but for other parameterizations it may actually be slightly decreasing over some range. The investment in future capital (as the tax rate on labor income) tends to be flat especially when the old are less successful at attracting large transfers from the young.

Given the weak response of the investment in future capital to the current level of capital, the politico-economic equilibrium we computed has a unique steady state, to which it converges rapidly.

\subsection{Comparative Statics}

We are now interested in studying how changes in the relevant parameters of the model affect the equilibrium of the economy at the steady state. We will consider four experiments that seem particularly relevant to me:

(i) a lower population growth, with $n=11 / 9$ (approximately $0.67 \%$ annual growth rate); this experiment is a first step towards the dynamic simulations of the next section;

(ii) an increase in the discount factor: we will increase $\beta$ by $10 \%$ compared to the baseline parameters;

(iii) an increase in the value the elderly attribute to the provision of the public good: we will increase $\xi$ by $10 \%$; 


$\begin{array}{cccccc}\text { Experiment } & \text { Baseline } & \text { (i) } & \text { (ii) } & \text { (iii) } & \text { (iv) } \\ \text { Parameters } & \text { Baseline } & n=11 / 9 & \beta \uparrow 10 \% & \xi \uparrow 10 \% & \sigma \uparrow 10 \% \\ & & & & & \phi \downarrow 11.61 \% \\ \hat{\tau}^{k} & 20 \% & 20.4 \% & 21.2 \% & 22.3 \% & 21 \% \\ \tau^{l} & 26.9 \% & 28.2 \% & 26.3 \% & 26.7 \% & 29.2 \\ g & & \downarrow 13.7 \% & \uparrow 2.9 \% & \uparrow 1.7 \% & \downarrow 4.5 \% \\ g / \mathrm{GNP} & 18.1 \% & 16.7 \% & 18 \% & 18.6 \% & 18.2 \% \\ T^{o} / \mathrm{GNP} & 9.1 \% & 11.9 \% & 9.2 \% & 9.1 \% & 11.2 \% \\ \frac{l \tau^{l}-T^{y}}{g} & 178.6 \% & 218.4 \% & 172.5 \% & 174.1 \% & 199.8 \% \\ \frac{R \tau^{k} k-T^{o}}{g} & -57.1 \% & -44.7 \% & -45 \% & -48.3 \% & -99.6 \%\end{array}$

Table 2: Comparative statics at the steady state

(iv) an increase in the curvature of the utility of the public good: we will increase $\sigma$ by $10 \%$ and adjust $\phi$ so that the marginal value of public spending at the baseline steady state is unchanged; by increasing the curvature, we offer more hold-up power to the groups that exploit it to extract rents.

Table 2 shows the main results of the experiments at the steady states. ${ }^{13}$

In the population growth experiment, the demographic effect of the change leads to an increase of the fraction of old people from $33 \%$ of the adult population to $45 \%$. The main variable that is affected by this change is the size of the government: as the old agents become relatively more numerous, their power in deciding the size of the government is increased. For the parameterization I show, the public good is more valuable to the young, and an aging population leads to a shrinking government. ${ }^{14}$ While the old agents are more powerful in setting the size of the government, their power is much more limited when it comes to negotiating higher net transfers from the young. When bargaining over intergenerational transfers, two offsetting effects come into play: while the old have more power, they also are more numerous and the benefit of a given level of net contribution by the young finances less transfers per capita to the old. As a consequence, while the resources the young generation transfers to the old one increase, the per capita transfer to the old declines, both as a consequence of a cut in the transfer and as a consequence of an increase in the tax rate on capital income. Table 2 shows how the increased burden leads to a sharing of the necessary sacrifices: in the steady state with lower population growth, the young contribute 2.18 units of the consumption good for each unit they receive back as public good, compared to a ratio of 1.79 in the steady state with high population growth; the old receive only 0.44 units of net transfers for each unit of the public good, compared to 0.57 units in the steady state with high population growth. We will comment in more detail the effects of a demographic shift by looking at dynamic simulations in the next section.

The second experiment studies what happens if the households are more patient and tend to save more during their lifetime. As table 2 shows, the differences between the equilibrium dictated by the baseline parameters and the new equilibrium is similar to the consequences of

\footnotetext{
${ }^{13}$ Variables without subscripts denote steady state values.

${ }^{14}$ For parameterizations in which the old have a higher marginal valuation of the public good in equilibrium, the size of the government increases.
} 
starting from a higher level of capital within an equilibrium, as the primary difference is the larger capital accumulation. Accordingly, we observe an increase in the provision of the public good and in social-security payments and a decrease in the tax rate on labor income, which are paid for by an increase in the tax rate on capital income. The "richer" among the old are forced to contribute more to the government budget as their wealth is larger and their demand for the public good is accordingly increased.

While the wealth effect is the dominant factor in the second experiment, the third one only looks at the consequences of an increase in the value the old attribute to the public good, which is measured by $\xi$. The results of the second and third experiment are similar, but the equilibrium in the third experiment is characterized by smaller savings and hence a smaller GNP: compared to the second experiment, the more-limited resources available in the third experiment lead to less spending, both in the public good and in transfers, and to higher taxes on all sources of income.

The final experiment shows the consequences of changing the hold-up power of each group in the economy. By increasing $\sigma$, we increase the concavity of the utility from public spending. The correction on $\phi$ means that the marginal value of the public vs. the private good is not changed at the steady state of the baseline equilibrium, but it still implies that the difference in utility over the threat-point is now larger. Because of this, we should expect the groups that take advantage of their hold-up power to obtain transfers to be even more successful when $\sigma$ is larger. The results presented in table 2 support this intuition: the net transfer enjoyed by the old at the expense of the young is largely increased, and the "poorer" among the old are particularly better off, as even the tax rates on capital income are raised to pay for much larger social-security transfers.

\section{Equilibria with Time-Varying Demographics}

In the previous section we discussed the effects of changing demographics on the steady state of the economy. In this section we look at the dynamic effects of such changes.

We will consider the effects of an increase in the share of the old in the population from $1 / 3$ to $45 \%$ dictated by a slowdown in the growth rate of the population from an annual $2.34 \%$ to an annual $0.67 \%$, i.e., from $n=2$ to $n=11 / 9$. The demographic transition happens in a single period (generation). ${ }^{15}$ The economy starts at the steady stated implied by $n=2$. All other parameters correspond to the baseline values indicated in Table 1.

We consider two experiments. In the first experiment the agents do not anticipate the demographic change, while in the second they do.

In our first experiment the economy starts at the initial steady state at time 0 , but the size of the newborn at time 1 is determined by $n_{1}=11 / 9$. At time 1 it becomes common knowledge that $n_{t}$ will be permanently $11 / 9$ for the indefinite future.

Figures 4-6 show the behavior of the variables in the transition when the demographic change is not anticipated. For the parameterization we chose, the transition to the new steady state is basically immediate; this happens because the capital per old person corresponding to the two steady states is almost the same (it is about $0.06 \%$ lower in the final steady state); for this reason, when the unexpected shock hits, the capital is already almost at its new steady state level. Even for other choices of the parameters, most of the adjustment happens within a couple

\footnotetext{
${ }^{15}$ The choice of limiting the demographic transition to one generation is made to clarify the economic effects at work. The algorithm used to compute the equilibrium can also compute longer transition paths.
} 
of generations: this is due to the rapid convergence to steady states we already observed. Figure 5 and 6 look at generational accounting in the transition. In figure 5, we look at the net payments from each generation to the government for each period: these are given by $\tau_{t}^{l} l_{t}-T_{t}^{y}$ for the young and $\tau_{t}^{k} R k_{t}-T_{t}^{o}$ for the old. Figure 6 looks at the present value of the contribution of each generation and takes also into account the value of the public good that is provided, i.e., it plots $\tau_{t-1}^{l} l_{t-1}-T_{t-1}^{y}+\frac{\tau_{t}^{k} R k_{t+1}-T_{t}^{o}}{R}-g_{t-1}-\frac{g_{t}}{R}$. For the old at time 0 , the contribution is computed as of time -1 , assuming that the economy was previously in the initial steady state. As we see, all generations have to contribute more resources to the government budget than they receive, either through transfers or through the public good: this reflects the repayment of the government debt implicit in the transfer to the initial old generation. At time 1 the demographic shock hits and the budget constraint of the government in present value is negatively affected: there will be less people in the future providing resources to it. In our model, the government reacts by reneging on part of its (implicit) debt with the old generation at time 1 and by increasing the resources requested from each individual among the young and the unborn as of time 1 . In most votingbased political processes, we actually observe the opposite effect for the old generation alive at time 1: since they become relatively more numerous, they are able to get even more advantages at the expense of the young and the unborn, leading the government to actually increase its net transfers to them. This does not happen when the generations bargain over the policy to be implemented: in this context, the power lost by the young due to their smaller number is more than compensated by their greater opposition to the transfers to the old generation, which have become more costly. As a consequence, the old generation is forced to accept both an increase in the taxes on capital income and a reduction in the transfers. If bargaining approximates reasonably the actual political process of the industrialized countries, old-age pensions will not be as crushing a burden as it is sometimes predicted, as the young generations will fight harder to reduce the entitlements. Evidence of such a tendency has recently emerged in many countries: e.g., the US planned a postponement of the retirement age in its reform of social security in the early '80s; a recently proposed revision of the CPI would also imply a cut in social-security benefits, and further measures that may reduce the benefits are being considered. However, our first experiment cannot explain the large increase in the social security benefits that happened in most countries before the ' $80 \mathrm{~s}$.

In our first experiment we looked at the consequences of an unanticipated change in the demographic structure of the population. Demographic changes evolve very slowly and are quite predictable, so it is interesting to look at what happens if we consider an economy where the shock is anticipated.

In the second experiment, the demographic transition is anticipated one generation ahead of the change; the economy starts in the initial steady state at time 0 and the change still becomes common knowledge at time 1 , but $n_{1}=2$ and $n_{t}=11 / 9$ only from $t=2$ on. Figures $7-10$ describe the response of the economy for this case. The first observation that these figures suggest is that the transition to the new steady state lasts longer than in the previous experiment: this happens both because the anticipation of the shock leads to policy changes before the shock actually occurs, and because the agents' response leads to changes in the investment in capital, so, when the demographic shock hits, the level of capital is no longer at its steady-state value and the economy needs some more time before settling at its new steady state.

To understand how the economy responds to demographics in this experiment, the crucial generation is the one that is young at time 1 , when the new path of $n_{t}$ becomes known, and is old 
at time 2 , when the change in the $n_{t}$ takes place. We will call this generation "the baby-boomers", as in the U.S. case the baby-boomers are the last generation before the demographic contraction and the demographic contraction has been anticipated since they started their adult life. In our model, from a private point of view, each baby-boomer anticipates that she will face a drop in the transfers she will receive when old, as the young in the next period will fight harder to reduce old-age entitlements; as a consequence, she will have an incentive to save more to partially offset the decline in the old-age consumption level. As a group, the baby-boomers realize however that an increase in their saving will reduce their bargaining power in period 2 and will lead to an even further cut in their net transfers; because of this, an increase in taxes, leading to an increase in the provision of the public good in the current period and to a reduction in saving, becomes a less-costly policy option. By supporting such a policy, the young affect not only their net transfer in the future period, but also the future provision of the public good; however, we already know that the parameter values we chose imply that the households value the public good much less in their old age than in their young age, so this effect is less important to them. As a consequence, in the given parameterization the baby-boomers support an increase in the provision of the public good in time 1, which they value highly, accompanied by an increase in the taxes on their labor income. This policy results in an increase in the hold-up power enjoyed by the generation that precedes the baby-boomers, i.e., the old at time 1: not only they can enjoy the benefits of a larger provision of the public good, but also they are able to extract even a larger surplus because of their increased hold-up power. As figure 10 shows, the generation that is old at time 1 is treated by the government even more favorably than previous steady-state generations; this is particularly true for the poorer among the old, which are the ones that exploit more fully their hold-up power: within the old generation, the income from capital is taxed at a higher rate in period 1 than in the previous steady state, with the resources being used to cover part of the increase in the social-security payments.

The results of our model are different if we choose a calibration in which the value of the public good in old age is higher and the old generation is actually contributing to part of its provision by paying more taxes on their capital income than the benefits they receive: in this case, the reduction in the size of the government and the increase in the net contribution start from time 1 and involve all generations alive in that period.

Having discussed what happens when the news of the demographic shock becomes known, we now look at period 2, when the shock takes place. Since $n_{t}$ is constant from now on, the equilibrium we are looking at is characterized by the new stationary policy rules from this period on; the actual policies are however affected by the fact that the state variable, i.e., the level of capital, is not at its steady-state value. Even though the policy of higher taxes has reduced the magnitude of the increase in saving of the baby-boomers, such an increase has taken place, and the economy starts from a higher level of capital per old person. Since the higher level of capital weakens the bargaining position of the old in the equilibrium we are considering, the baby-boomers are called to contribute more in their old age than future generations will be: this is reflected in higher taxes on the capital income. The government uses these revenues to provide more of the public good, and to pay somewhat higher pensions than the ones that will prevail afterwards: the latter effect comes from the usual relationship between the size of the government and the hold-up power enjoyed by the poorer among the old, which implies that a larger government is associated with more social-security transfers. Compared to future generations, the young at time 2 benefit primarily from consuming more of the public good in their young age; they also get a slightly 
lower tax rate on their labor income than future generations will, but this effect is so small that it is impossible to see it on the graph in figure 7.

The main difference between experiments 1 and 2 lies therefore in the behavior of the generation that precedes the demographic transition, i.e., the baby-boomers: their bargaining position is the one that is weakened most by the anticipation of the shock and their net contribution to the government is higher if the shock is anticipated than it is if the shock is unanticipated; ${ }^{16}$ the generation that precedes the baby-boomers and the one that follows them receive the benefits of this higher contribution.

The model we considered can therefore explain a temporary increase in the social-security transfers when an increase in the fraction of the elderly is anticipated for the future; this could partly explain the increases in old-age benefits we observed in the '60s and '70s. At the same time, the observation of a past increase in such benefits is consistent with the prediction of a significant contraction in the social-security transfers that will be paid out to the old in the future, after the relative size of the young cohort has shrunk significantly.

\section{Endogenous factor prices}

In this section we study how the results change if the interest rate and the wage vary with the relative amount of capital and labor in the economy. Because of the demographic transition, capital will become more abundant compared to labor in the next decades; this is likely to change factor prices significantly.

The production function is now assumed to be Cobb-Douglas as in equation (4). We calibrate the share of capital to be $1 / 3$, whereas $A$ is chosen so that we get an annual interest rate of approximately $6 \%$, the same as in the model with a linear technology. We also use $\beta, \xi, \phi$ and $\sigma$ to match the same features we matched in the model with exogenous factor prices.

The parameter values for this calibration are contained in table 3. Compared with the case of exogenous factor prices, there are two major differences. First, the utility from government spending must now be higher than it was when factor prices were given. This is because distortions to the labor supply now reduce the rate of return on capital, thereby giving an additional reason for keeping government spending low. Second, the old must be more patient, for otherwise the equilibrium rate of return on capital would be too high. However, the relative valuation of the public good in young and old age should not be affected as much, for otherwise we would observe too many taxes being imposed on the old; as a consequence, $\xi$ needs to be reduced. The results I present would be very similar even if we used the same values of $\beta, \xi, \phi$ and $\sigma$ that were used in the experiment with exogenous prices. ${ }^{17}$

Introducing endogenous prices does not have a large effect on the government policy, with the exception of taxes on labor income. As we already observed, the behavior of taxes on labor income is the least robust aspect of the calibration. In the calibration with endogenous prices, taxes on labor income are an increasing function of the level of capital. This is partly due to the

\footnotetext{
${ }^{16}$ This can be seen by comparing figures 6 and 10; the demographic shock hits at time 1 in figure 6 and at time 2 in figure 10, so the appropriate comparison is between the contribution of the generation dying at the end of period 1 in figure 6 and the contribution of the generation dying at the end of period 2 in figure 10 .

${ }^{17}$ Qualitatively, the only difference is in the behavior of the tax on capital during the transition; using the values of $\beta, \xi, \phi$ and $\sigma$ from table 1 , the tax rate on capital is lower at the new steady state than it is in the initial steady state.
} 


$\begin{array}{cc}\gamma & 1 \\ \beta & 0.4362 \approx 0.97^{30} \\ \xi & 0.3984 \\ A & 0.8504 \\ V\left(g_{t}\right) & \phi \frac{g^{1-\sigma}}{1-\sigma} \\ \phi & 1.084 \\ \sigma & 0.6622 \\ n & 2 \approx 1.0234^{30}\end{array}$

Table 3: Parameters for the economy with endogenous prices

fact that a larger level of capital leads also to more income for the young through its effect on the wage rate. The additional revenues from labor-income taxes are spent on providing more of the public good; accordingly, government spending is more responsive to the level of capital when factor prices are endogenous.

The experiments with demographic transitions also reveal a similar pattern to the one we observed with exogenous prices, with two differences:

(i) In the experiment with endogenous prices, the capital per old person in the initial steady state is lower than in the final steady state, so the economy experiences a longer transition, during which the size of the government sector gradually expands as the economy grows richer. As a consequence, government spending and pensions are cut in the short run more than they will be in the long run, after the transition has completed.

(ii) Even when the shock is anticipated, the calibration with endogenous prices does not predict a short-run increase of transfers and government spending in response to the aging of the population. The baby-boomer generation is still discouraged from saving, and accumulates less capital per capita than any other generation. With exogenous factor prices, the lower savings were a consequence of higher taxes in the short run, which were accompanied by more spending and transfers to the old. When factor prices are endogenous, the decline in the expected rate of return is sufficient to discourage saving and hence the generation that precedes the demographic contraction is less likely to advocate a spendthrift government.

The experiments with endogenous factor prices confirm that the most robust result from the simulations is the positive connection between the size of the government sector and the transfers per capita that are paid to the old. Future research will inquire whether the quantitative connection that we obtain in the simulations matches what we observe in the data. ${ }^{18}$

\section{Conclusions and directions for future research}

The main purpose of this paper was to study how a political system determines transfers across different generations, by looking at a broad set of fiscal instruments rather than at a single aspect

\footnotetext{
${ }^{18}$ The qualitative connection between general spending and pensions is documented by cross-country and timeseries regressions (see Mulligan and Sala i Martin [18]). Lambertini and Azariadis [16] identify health and education as the primary fields in which the U.S. government has expanded in the last century, besides social security.
} 
of the government policy. In particular, we showed that in many instances looking at socialsecurity transfers alone might give a misleading picture of generational accounting, as changes in the taxes collected on capital income might sometimes more than offset any changes in old-age pension payments.

We showed how the different nature of tax liabilities for the young and the old can explain why the old receive large (gross) lump-sum transfers while the young receive little or none. In an environment where the government policy is determined sequentially, the tax base of the old is determined by their past decisions, whereas the tax base of the young is determined by their current decisions: for this reason, the distortions arising from taxation are a sunk cost for the old and therefore they are more willing to accept an increase in the tax rate in exchange for transfers.

The paper suggests also a connection between the general size of the government and the level of transfers. When the role of the government as a provider of public goods is more important, the hold-up power of any group that values the public goods less is enhanced and can be used to extract larger transfers.

We also looked at the consequences of aging of the population on the fiscal policy of the government, on generational accounting and on social security. We showed that an anticipated increase in the fraction of the elderly may lead to a temporary increase in government spending, both in goods and in transfers; the temporary increase is followed by a permanent contraction in the size of the government after the shock hits. By looking at generational accounting, we were able to observe how the anticipation of the shock may hurt the "baby-boomers", i.e., the first generation that will be old when the shock hits; this result stems from the strategic interaction among cohorts that is introduced by looking explicitly at a dynamic model of the political system.

It would be interesting to contrast the results we obtain here with an alternative political system, in which voting paradoxes are solved by giving someone agenda-setting powers.

In my opinion, three extensions of the current model are particularly important to reach a better understanding of the economic problem at hand. First, it would be interesting to study an economy where each generation lives for more than two periods. In the model we considered, all the capital is in the hands of the old, which is a very crude description of reality; in practice, the tax base for capital-gains taxes includes many middle-aged people who are still working, and this may be important in the determination of the policy. By looking at a model where generations live for more than two periods, we would also relieve the tension in the calibration between a reasonable growth rate for the population and a reasonable fraction of retired people in the economy.

A second extension would explicitly look at the role of government debt. By imposing a balanced-budget policy, we significantly restricted the possibilities for intergenerational distribution. A demographic shock is likely to interact significantly with the magnitude of government debt, and this may be relevant for the determination of the fiscal policy, especially during the transition phase.

Finally, more research is needed on the model of the political system that is best suited to describe how fiscal policies are actually determined. As we saw, the present model can justify large net transfers of resources from the young to the old only by assuming that the old have a low valuation of the public good. Within the context of bargaining, it would be helpful to think more at how the threat point itself is determined. More in general, it would be interesting to explore alternative theories of how a multidimensional policy is determined. 


\section{A Proofs}

\section{A.1 Proof of Proposition 2}

We need to distinguish four cases.

(i) The inequality in (20) is strict and $k_{t}>0$. This is the interesting case, in which all factors of production are in strictly positive supply at time $t$. In order to prove that a temporary competitive equilibrium exists and is unique for a given $\left(k_{t+1}, \tau_{t}^{k}, T_{t}^{y}, T_{t}^{o}\right)$, we need to show that equations (8), (7), (9), (12), (13), (14), (15), (16) as well as equation (10) evaluated at time $t$, have a solution in $\left(c_{t}^{y}, c_{t}^{o}, l_{t}, L_{t}, K_{t}, \tau_{t}^{l}, g_{t}, w_{t}, R_{t}\right)$ and that this solution is unique.

We proceed by recursive substitution; by proceeding in an appropriate order, we solve each equation in one variable as a function of the initial parameters $\left(k_{t+1}, \tau_{t}^{k}, T_{t}^{y}, T_{t}^{o}\right)$ and $\pi_{t+1}\left(k_{t+1}\right)$ and of variables that were determined by previous equations.

When (20) is a strict inequality, equation (8) has a unique solution in $w_{t}\left(1-\tau_{t}^{l}\right)$ given by

$$
w_{t}\left(1-l_{t}\right)=\frac{\gamma k_{t+1}}{\beta}+\frac{\gamma \pi_{t+1}^{o}\left(k_{t+1}\right)}{\beta \pi_{t+1}^{R}\left(k_{t+1}\right)\left(1-\pi_{t+1}^{k}\left(k_{t+1}\right)\right)}>0
$$

We can then get a unique solution for $l_{t}$ from (7):

$$
l_{t}=\frac{1+\beta}{\gamma}-\frac{T_{t}^{y} \beta \pi_{t+1}^{R}\left(k_{t+1}\right)\left(1-\pi_{t+1}^{k}\left(k_{t+1}\right)\right)+\pi_{t+1}^{o}\left(k_{t+1}\right)}{\gamma\left[\pi_{t+1}^{R}\left(k_{t+1}\right)\left(1-\pi_{t+1}^{k}\left(k_{t+1}\right)\right) k_{t+1}+\pi_{t+1}^{o}\left(k_{t+1}\right)\right]}
$$

Using (8), simple algebra shows that $l_{t}>0$ whenever (20) is a strict inequality. Equation (9) has then a unique solution in $c_{t}^{y}$, given by

$$
c_{t}^{y}=\frac{k_{t+1}}{\beta}+\frac{\pi_{t+1}^{o}}{\pi_{t+1}^{R}\left(k_{t+1}\right)\left(1-\pi_{t+1}^{k}\left(k_{t+1}\right)\right)}>0
$$

Equations (15) and (16) yield unique solutions for $L_{t}$ and $K_{t}$, both of which will be strictly positive. We can use these solutions to get unique factor prices $R_{t}$ and $w_{t}$ that solve (12) and (13). Since we previously determined uniquely $w_{t}\left(1-\tau_{t}^{l}\right)$, from $w_{t}$ we infer a unique value for $\tau_{t}^{l}$. Notice that $\tau_{t}^{l}<1$ since both the solution for $w_{t}\left(1-\tau_{t}^{l}\right)$ and for $w_{t}$ are strictly positive. Having determined $R_{t}$, we get a unique solution for $c_{t}^{o}$ from equation (10); this solution is nonnegative. Finally, we can substitute all of the previous information into (14) and solve this equation for a unique value of $g_{t}$. Simple algebra shows that this solution will be nonnegative when (21) holds.

(ii) The inequality in (20) is strict, but $k_{t}=0$. We proceed as in the previous section, but now $R_{t}$ cannot be uniquely determined by equation (12); any positive value for $R_{t}$ can be part of a temporary competitive equilibrium. Nonetheless, $c_{t}^{o}$ is still uniquely determined by equation (10), since $R_{t}$ drops out of the equation when $k_{t}=0$, and it is still nonnegative; this implies that $g_{t}$ is uniquely determined as well, and is nonnegative because of equation (21). 
(iii) (20) holds with equality and $k_{t}>0$. In this case, equation (8) is automatically satisfied and implies that

$$
\frac{\beta w_{t}\left(1-\tau_{t}^{l}\right)}{\gamma}-\frac{\pi_{t+1}^{o}\left(k_{t+1}\right)}{\pi_{t+1}^{R}\left(k_{t+1}\right)\left(1-\pi_{t+1}^{k}\left(k_{t+1}\right)\right)} \leq \frac{\beta T_{t}^{y}}{1+\beta}-\frac{\pi_{t+1}^{o}\left(k_{t+1}\right)}{(1+\beta) \pi_{t+1}^{R}\left(k_{t+1}\right)\left(1-\pi_{t+1}^{k}\left(k_{t+1}\right)\right)}
$$

This inequality implies that $l_{t}=0$ is the unique solution to (7). As before, we can determine uniquely $c_{t}^{y}$ from (9); we will now obtain

$$
c_{t}^{y}=\frac{T_{t}^{y}+\frac{\pi_{t+1}^{o}\left(k_{t+1}\right)}{\pi_{t+1}^{R}\left(k_{t+1}\right)\left(1-\pi_{t+1}^{k}\left(k_{t+1}\right)\right)}}{1+\beta} \geq 0
$$

$K_{t}$ and $L_{t}$ follow uniquely from (15) and (16), but now $L_{t}=0$; while $R_{t}$ is uniquely determined by (12), now $w_{t}$ is no longer uniquely determined, nor is $\tau_{t}^{l}$. In order to have a competitive equilibrium $w_{t}$ and $\tau_{t}^{l}$ must be chosen so that $w_{t} \geq F_{L}\left(\frac{k_{t}}{1+n_{t}}, 0\right)$ and $w_{t}\left(1-\tau_{t}^{l}\right)$ is sufficiently small that (22) is satisfied. If $F$ satisfies Inada conditions, this case would imply an infinite wage rate accompanied by a $100 \%$ tax on the labor supply; this would never be the outcome of bargaining, so this case becomes uninteresting. The temporary competitive equilibrium is completed by solving (10) for $c_{t}^{o}$ (which will yield a nonnegative number) and (14) for $g_{t}$; equation (22) is the condition that guarantees nonnegativity of $g_{t}$ in this case.

(iv) (20) holds with equality and $k_{t}=0$. We can proceed as in the previous case and establish that $l_{t}=0$. In this case there is no production at time 0 , so both generations would be infinitely unhappy and would always avoid this solution. The restriction (22) can only be met if $T_{t}^{y}=0$ and $T_{t}^{o}=0$. Equation (20) implies thus $k_{t+1}=0$, and $c_{t}^{y}=0, c_{t}^{o}=0$ follow from (9) and (10). We also obtain $K_{t}=0$ and $L_{t}=0$. Factor prices $w_{t}$ and $R_{t}$ can be set at any value that exceeds $F_{L}(0,0)$ and $F_{K}(0,0)$; the tax rate on labor should be set sufficiently high that (30) holds. Finally (14) requires $g_{t}=0$.

QED.

\section{A.2 Proof of Proposition 3}

When (20) is violated, it follows immediately that $k_{t+1}$ cannot satisfy equation (8), which is required for a temporary competitive equilibrium. For the other two cases, we can proceed exactly as we did in proving proposition 2; as we observed in that proof, equation (21) or (22) is the condition that ensures that (14) has a nonnegative solution in $g_{t}$. When such condition is violated, we cannot find a nonnegative solution in $g_{t}$, and hence no temporary competitive equilibrium exists. QED.

\section{A.3 Proof of Proposition 4}

Following the same steps as in the proof of proposition 2, we obtain that all variables except the current tax rate on capital and the transfer to the old must be the same in the two equilibria; in particular, the time- $t$ allocation will be the same; because $\pi_{t+1}$ and $k_{t+1}$ are the same in both temporary competitive equilibria, expectations about future consumption and provision of the public good are also the same. It then follows from (1) that the utility of both generations is the same in the two equilibria. QED. 


\section{A.4 Proof of (the general version of) Proposition 5}

In this appendix, we work with the general case of a sequence of distributions of capital holdings, rather than just with two groups. We consider conditional bargaining among the old agents, assuming that they start with an average level $k_{t}$ of capital and that the politico-economic equilibrium sets their average consumption at $c_{t}^{o}$, the tax rate on capital at $\tau_{t}^{k}$, the level of government spending per capita at $g_{t}$ and the interest rate at $R_{t}$. We also assume that the politico-economic equilibrium implies an interest rate $R_{t}^{*}$ if the threat-point policy is implemented at time $t$.

In the main text, we divide the old in two groups, one of which has $(1-\alpha) \hat{k}$ units of capital in excess of $k_{t}$, while the other is $\alpha \hat{k}$ units short of $k_{t}$. We then take limits as $\hat{k} \rightarrow 0$. For the general case, we consider more-general deviations from uniform capital holdings and a moregeneral convergence criterion. In this case, we let $F_{i}$ be a cdf representing the distribution of capital among the old. We want this distribution to be degenerate on $k_{t}$ in the limit; we will define below the precise convergence criterion.

The following lemma is useful in establishing one of the properties we need the sequence $\left\{F_{i}\right\}_{i=1}^{\infty}$ to satisfy.

Lemma 1 Let an old person compare the utility that she receives from the following policies and factor prices:

(i) a tax rate on capital $\tau_{t}^{k}$, a transfer $T_{t}^{o}, g_{t}$ units of public good per capita and an interest rate $R_{t}$;

(ii) no taxes on capital, no transfers, no provision of the public good and an interest rate $R_{t}^{*}$.

The surplus the person receives from the former policy is nonincreasing in her capital holdings, and it is strictly decreasing if $T_{t}^{o}>0$.

Proof. The surplus an old person with $k$ units of capital receives is given by

$$
\log \left[T_{t}^{o}+\left(1-\tau_{t}^{k}\right) R_{t} k_{t}\right]+\xi V\left(g_{t}\right)-\log \left(R_{t}^{*} k_{t}\right)=\log \left[\frac{\frac{T_{t}^{o}}{k_{t}}+\left(1-\tau_{t}^{k}\right) R_{t}}{R_{t}^{*}}\right]+\xi V\left(g_{t}\right)
$$

QED.

We assume that $\left\{F_{i}\right\}_{i=1}^{\infty}$ satisfies the following conditions:

(i) there exists an $i_{0}$ such that the support of $F_{i}$ is a subset of $(\underline{k},+\infty)$ for each $i>i_{0}$.

(ii) if $\frac{\left(1-\tau_{t}^{k}\right) R_{t}}{R_{t}^{*}}<1$, then there exists an $i_{1}$ such that the support of $F_{i}$ is a subset of $(0, \bar{k})$ for each $i>i_{1}$, where $\bar{k}$ satisfies the following

$$
\log \left[T_{t}^{o}+\left(1-\tau_{t}^{k}\right) R_{t} \bar{k}\right]+\xi V\left(g_{t}\right)-\log R_{t}^{*} \bar{k}>\underline{D U}>0
$$

(iii) $\int_{\mathbb{R}^{+}} k d F_{i}(k)=k_{t} \quad i \in \mathbb{N}$ 
(iv)

$$
\lim _{i \rightarrow \infty} \frac{\int_{\mathbb{R}^{+}}\left|k-k_{t}\right|^{3} d F_{i}(k)}{\int_{\mathbb{R}^{+}}\left(k-k_{t}\right)^{2} d F_{i}(k)}=0
$$

(v) For each $i, F_{i}$ is not a degenerate distribution on $k_{t}$.

The first condition requires every old person to have an amount of capital that is positive and uniformly bounded away from 0 in the limit. The second condition implies that, in the limit, every old person prefers the policy prescribed by the politico-economic equilibrium over the threatpoint policy, and each person gets a surplus that is bounded away from 0 . The third condition ensures that the average level of capital per old person is $k_{t}$. Finally, the fourth condition states the convergence criterion that we will use $^{19}$ and the last condition requires the distribution to be nondegenerate, as we already know that the solution is indeterminate when all the mass is concentrated at $k_{t}$.

The following theorem provides a sufficient condition for convergence according to the criterion dictated by (34).

Proposition 6 Let $X$ be a random variable with finite third moment, and let $\left\{\epsilon_{i}\right\}_{i=1}^{\infty}$ be a nonnegative sequence converging to 0 . Let $F_{i}$ be the cdf of $k_{t}+\epsilon_{i} X$. Then $\left\{F_{i}\right\}_{i=1}^{\infty}$ satisfies equation (34).

Proof.

$$
\frac{\int_{\mathbb{R}^{+}}\left|k-k_{t}\right|^{3} d F_{i}(k)}{\int_{\mathbb{R}^{+}}\left(k-k_{t}\right)^{2} d F_{i}(k)}=\epsilon_{i} \frac{E\left(|X|^{3}\right)}{E\left(X^{2}\right)} \rightarrow_{i \rightarrow \infty} 0
$$

QED.

The two-group case we consider in the main text is one example in which proposition 6 applies. In that example, the random variable $X$ takes the values $-\alpha$ with probability $1-\alpha$ and $1-\alpha$ with probability $\alpha$, and $\hat{k}$ plays the role of $\epsilon_{i}$.

We are now ready to state and prove the general version of proposition 5 .

Proposition 7 Assume an ESPEE is such that $k_{t}>0 \forall t$ and such that the utility of either generation at any point in time is strictly above its threat point. Let $\left(c_{t}^{o}, g_{t}, \tau_{t}^{k}, T_{t}^{o}, R_{t}\right)$ be respectively consumption by the elderly, per capita provision of the public good, the tax rate on capital, transfers to the old and the interest rate on the equilibrium path. Let $R_{t}^{*}$ be the interest rate that the politico-economic equilibrium predicts if the threat-point policy is implemented at time $t$. Let $\left\{F_{i}\right\}_{i=1}^{\infty}$ be a sequence of cdf's satisfying the properties (i)-(v) above. Let us consider the tax rate on capital and the lump-sum transfer to the old that arise from conditional bargaining among the old given their average consumption level $c_{t}^{o}$ and the level of provision of the public good $g_{t}$ when capital holdings at time $t$ are distributed according to $F_{i}$. As $i \rightarrow \infty$, the tax rate on capital and the lump-sum transfer converge to $\left(\tau_{t}^{k}, T_{t}^{o}\right)$ if and only if

$$
\left\{\begin{array}{l}
1-\tau_{t}^{k}=\frac{c_{t}^{o}}{R_{t} k_{t}\left(1+D U_{t}\right)} \\
T_{t}^{o}=\frac{D U_{t}}{1+D U_{t}} c_{t}^{o}
\end{array}\right.
$$

\footnotetext{
${ }^{19}$ This convergence criterion is neither implied nor it implies the most commonly used criteria, such as weak or strong convergence, or convergence in a $L^{p}$ norm.
} 
where $D U_{t}$ is the difference in utility between what an old agent gets and her threat point, evaluated when there is no heterogeneity, i.e.,

$$
D U_{t} \equiv \log c_{t}^{o}+\xi V\left(g_{t}\right)-\log \left(R_{t}^{*} k_{t}\right) .
$$

Proof. Given the average consumption by the old $\left(c_{t}^{o}\right)$ and the average capital holdings, a tax rate on capital $\tau^{k}$ implies a lump-sum transfer $T^{o}=c_{t}^{o}-\left(1-\tau^{k}\right) R_{t} k_{t}$. We can therefore substitute out $T^{o}$ and write the conditional bargaining problem as one of solving ${ }^{20}$

$$
\max _{\tau^{k}} \int_{\mathbb{R}^{+}} \log \left\{\log \left[c_{t}^{o}+\left(1-\tau^{k}\right) R_{t}\left(k-k_{t}\right)\right]+\xi V\left(g_{t}\right)-\log \left(R_{t}^{*} k\right)\right\} d F_{i}(k)
$$

s.t.

$$
\log \left[c_{t}^{o}+\left(1-\tau^{k}\right) R_{t}\left(k-k_{t}\right)\right]+\xi V\left(g_{t}\right)-\log \left(R_{t}^{*} k\right) \geq 0 \quad \forall k \in \operatorname{supp}\left(F_{i}\right)
$$

and $^{21}$

$$
\left(1-\tau^{k}\right) k_{t} \leq c_{t}^{o}
$$

If there is no $\tau^{k}$ that can satisfy the constraints, then no agreement would be possible among the old, and the original bargaining with the young would have to be more generous towards the old in order to support positive levels of $g_{t}$. However, because of assumption (ii) on $F_{i}$, when $i>i_{1}$ there is a neighborhood of $\tau_{t}^{k}$ for which the surplus is strictly positive and bounded away from 0 for all levels of capital in the support of $F_{i}$. In this case, the set of values of $\tau^{k}$ that satisfy the constraints is nonempty. The function to be maximized in (38) is strictly concave in $\tau^{k}$, and the sets implied by (39) and (40) are convex. This implies that there is a unique local maximum which is also a global maximum. We are interested in establishing when this maximum is converging to $\tau_{t}^{k}$. Because of assumptions (i) and (ii), there is a neighborhood $U_{\tau_{t}^{k}}$ of $\tau_{t}^{k}$ in which we can apply the dominated convergence theorem to the first-order conditions (38) and in which the constraints are not binding. Let $\tilde{\tau}_{i}^{k}$ be the solution to maximizing (38) s.t. (39) and (40). When $\tilde{\tau}_{i}^{k} \in U_{\tau_{t}^{k}}$, it satisfies thus the first-order condition

$$
-\int_{\mathbb{R}^{+}} \frac{R_{t}\left(k-k_{t}\right)}{\left\{\log \left[c_{t}^{o}+\left(1-\tilde{\tau}_{i}^{k}\right) R_{t}\left(k-k_{t}\right)\right]+\xi V\left(g_{t}\right)-\log \left(R_{t}^{*} k\right)\right\}\left[c_{t}^{o}+\left(1-\tilde{\tau}_{i}^{k}\right) R_{t}\left(k-k_{t}\right)\right]} d F_{i}(k)=0
$$

Let

$$
G\left(k, \tau^{k}\right) \equiv \frac{R_{t}\left(k-k_{t}\right)}{\left\{\log \left[c_{t}^{o}+\left(1-\tau^{k}\right) R_{t}\left(k-k_{t}\right)\right]+\xi V\left(g_{t}\right)-\log \left(R_{t}^{*} k\right)\right\}\left[c_{t}^{o}+\left(1-\tau^{k}\right) R_{t}\left(k-k_{t}\right)\right]}
$$

\footnotetext{
${ }^{20}$ In equation (38), it is convenient to take the logarithm of the objective function to be maximized. This avoids the need to write the product of a continuum of terms (replacing it with an integral) and yields also nicer first-order conditions.

${ }^{21}$ This proof ignores the constraint $\tau^{k} \leq 1$. This is done just to save space; it is straightforward to add this constraint to it. Note that in an ESPEE equation (36) implies that $\tau_{t}^{k}<1$.
} 
$G$ is the integrand in (41). It is differentiable 3 times as a function of $k$ in the support of $F_{i}$ when $\tau^{k} \in U_{\tau_{t}^{k}}{ }^{22}$ We can then use a Taylor series expansion to rewrite (41) as

$$
\begin{gathered}
G\left(k_{t}, \tilde{\tau}_{i}^{k}\right) \int_{\mathbb{R}^{+}} d F_{i}(k)+G_{k}\left(k_{t}, \tilde{\tau}_{i}^{k}\right) \int_{\mathbb{R}^{+}}\left(k-k_{t}\right) d F_{i}(k) \\
+\frac{G_{k k}\left(k_{t}, \tilde{\tau}_{i}^{k}\right)}{2} \int_{\mathbb{R}^{+}}\left(k-k_{t}\right)^{2} d F_{i}(k)+\frac{1}{6} \int_{\mathbb{R}^{+}} G_{k k k}\left(k_{t}+\lambda\left(k, \tilde{\tau}_{i}^{k}\right)\left(k-k_{t}\right), \tilde{\tau}_{i}^{k}\right)\left(k-k_{t}\right)^{3} d F_{i}(k)=0
\end{gathered}
$$

where $\lambda\left(k, \tilde{\tau}_{i}^{k}\right) \in(0,1)$. Notice that $G\left(k_{t}, \tilde{\tau}_{i}^{k}\right)=0$ and $\int_{\mathbb{R}^{+}}\left(k-k_{t}\right) d F_{i}(k)=0$. The first two terms in the Taylor series expansion are thus identically zero.

Let $H_{i}$ be the convex hull of the support of $F_{i}$. Assumptions (iii) and (v) imply that $k_{t}$ is in the interior of $H_{i}$ and hence

$$
k \in \operatorname{supp}\left(F_{i}\right) \Longrightarrow k_{t}+\lambda\left(k, \tilde{\tau}_{i}^{k}\right)\left(k-k_{t}\right) \in H_{i}
$$

Because the left-hand-side of (39) is monotone in $k$, when (39) is satisfied, it is also satisfied by all values in $H_{i}$.

Simple but tedious algebra shows that $G_{k k k}$ is bounded as a function of $k \in H_{i}$ when $\tilde{\tau}_{i}^{k} \in U_{\tau_{t}^{k}}$. Equation (34) implies thus that the solution to (43) must involve $G_{k k}\left(k_{t}, \tilde{\tau}_{i}^{k}\right) \rightarrow_{i \rightarrow+\infty} 0$. Since $G_{k k}$ is a continuous function of $\tau^{k}$, this implies that $\left\{\tilde{\tau}_{i}^{k}\right\}_{i=1}^{\infty}$ should converge to the solution of $G_{k k}\left(k_{t}, \tau^{k}\right)=0$. Therefore, if

$$
\exists \bar{i}: \tilde{\tau}_{i}^{k} \in U_{\tau_{t}^{k}} \forall i>\bar{i}
$$

then $\tilde{\tau}^{k} \equiv \lim _{i \rightarrow \infty} \tilde{\tau}_{i}^{k}$ must satisfy ${ }^{23}$

$$
\left(1-\tilde{\tau}^{k}\right) R_{t} k_{t}\left(1+D U_{t}\right)-c_{t}^{o}=0
$$

Notice that (45) is a necessary condition for $\left\{\tilde{\tau}_{i}^{k}\right\}_{i=1}^{\infty}$ to converge to $\tau_{t}^{k}$. Therefore, if $\left\{\tilde{\tau}_{i}^{k}\right\}_{i=1}^{\infty}$ converges to $\tau_{t}^{k}$, then $\tau_{t}^{k}=\tilde{\tau}^{k}$, which implies (36). Conversely, if (36) is satisfied, $\tau_{t}^{k}$ satisfies equation (46). Furthermore, $G_{k k}$ is a continuous function of $k \in H_{i}$ when $\tau^{k} \in U_{\tau_{t}^{k}}$; $G_{k k k}$ is bounded in the same range. Hence, there exists a sequence of taxes that satisfies (43) when $i$ is sufficiently large and converges to $\tau_{t}^{k}$. Because (43) is a sufficient condition for a maximum, it follows that the sequence that satisfies (43) is the sequence of maximizers of (38). QED.

\section{B Computation of the Annualized Tax Rate on Capital Income}

With the timing of the economy described in the paper and the definition of $\tau_{t+1}^{k}$, one unit of the good invested at time $t$ yields $R_{t+1}\left(1-\tau_{t+1}^{k}\right)$ units at time $t+1$. If we define $\hat{\tau}_{t+1}^{k}$ as the tax rate that applies every year on the interest earned from an investment between $t$ and $t+1$ and we assume a constant interest rate, we find that one unit of the good invested today will yield $\left[1+r_{t+1}\left(1-\hat{\tau}_{t+1}^{k}\right)\right]^{30}$ units 30 years from now, where $1+r_{t+1}$ is the annual gross return from investment, i.e. $r_{t+1}=R_{t+1}^{1 / 30}-1$.

\footnotetext{
${ }^{22}$ It is actually a $C^{\infty}$ function, but being 3 times differentiable is all that is required for our proof.

${ }^{23}$ Equation (46) follows from simplifying $G_{k k}\left(k_{t}, \tilde{\tau}^{k}\right)=0$.
} 
We compute the annualized tax on capital income by imposing equality of the two expressions:

$$
R_{t+1}\left(1-\tau_{t+1}^{k}\right)=\left[1+r_{t+1}\left(1-\hat{\tau}_{t+1}^{k}\right)\right]^{30}
$$

Solving for $\hat{\tau}_{t+1}^{k}$ and substituting for $r$ we obtain

$$
\hat{\tau}_{t+1}^{k}=1-\frac{\left[R_{t+1}\left(1-\tau_{t+1}^{k}\right)\right]^{1 / 30}-1}{R_{t+1}^{1 / 30}-1}
$$

\section{Solution Algorithm in a Stationary Environment}

The solution algorithm works according to the following steps:

(i) We form a grid for the state variable $\left(k_{t}\right)$. Since I will use Chebyshev-polynomial interpolation, ${ }^{24}$ I select by trial and error a suitable interval $[\underline{k}, \bar{k}]$, and I select the grid point at the roots of the $d+1$ st order Chebyshev polynomial, where $d$ is the order of the polynomial interpolation.

(ii) We provide an initial guess for the rule $\pi$ as a function of the capital next period at the grid points. The guess only requires the net expected rate of return from investment $\pi^{R}().(1-$ $\left.\pi^{k}().\right)$, the expected transfers to the old $\pi^{o}$ and the expected government spending $\pi^{g}$. The usual starting point was $\pi^{R} \equiv R \pi^{k} \equiv 0, \pi^{o} \equiv 0, \pi^{g} \equiv g$, where $R$ and $g$ are constant. I also tried different guesses, and I converged to the same equilibrium, as long as the initial $\pi$ let to a unique equilibrium. Further research is needed for the case in which the initial $\pi$ leads to multiple equilibria, as well as for the case in which the initial $\pi$ is not continuous and hence cannot be approximated by Chebyshev polynomials or piecewise linear interpolation.

(iii) Given the previously mentioned functions evaluated at the grid points, we use Chebyshev polynomial interpolation to approximate the policy for points within $[\underline{k}, \bar{k}]$. I chose the maximum degree of the polynomial to be $d=30$, but this is already quite higher than what is required to get a very good approximation.

(iv) Given the expected policy, we compute the temporary competitive equilibrium under the threat-point policy. Following the steps of the proof of proposition 2, this can be reduced to solving a system of two nonlinear equations in $k^{*}$ and $l^{*}$, with all of the other variables following from the recursive substitutions. ${ }^{25}$

(v) Given the expected rule $\pi$, we compute the threat-point utilities for the young and the old at the grid points.

(vi) Given the expected rule $\pi$, we solve the bargaining problem of maximizing (23). We use equation (25) as a restriction to break the indeterminacy of the optimal solution. From the previous maximization, we get a new rule.

(vii) We iterate on steps (iii) through (v) until convergence.

\footnotetext{
${ }^{24}$ I also tried using piecewise linear interpolation, with similar results. Polynomial interpolation seems preferable both because the functions to be studied seem to be very smooth and because the nonlinear optimization algorithm works best with smooth functions.

${ }^{25}$ Since we are looking for stationary equilibria, we can omit the time subscript for $k^{*}$.
} 


\section{Solution Algorithm for the Demographic-Shock Experiment}

(i) We start the economy at the initial steady state of the stationary equilibrium associated with the initial growth rate of the population; the stationary equilibrium is computed according to the procedure set forth in $\mathrm{C}$, and we use the implied transition function for capital to find the steady state.

(ii) We specify the new path for $n_{t}$. This is assumed to become common knowledge at time 1 , so we have perfect foresight from time $1 \mathrm{on}$. We assume that $n_{t}$ becomes constant from some period $T$ on.

(iii) From period $T$ on, we compute the stationary equilibrium associated with the new population growth rate; this is done again according to the procedure described in $\mathrm{C}$.

(iv) For the periods between 1 (included) and $T$ (excluded), we compute backwards the rules $\pi_{t}$, following the procedure described in (iii)-(v) of C: we start from the rule we computed for period $T$, and we solve backwards for all policy functions up to period 1 . While the policy functions are thus the same after period $T$, because of the stationarity assumption, the policy functions will in general change over time between time 1 and time $T$, as $n_{t}$ will usually be different from its new steady state value that will be reached from $T$ on.

(v) We use the transition functions for capital that can be derived from the policy functions to compute the path for capital, starting from the initial steady-state level. From the capital level, we can then infer the government policy by looking at the policy functions, and from there we can infer the choices of the private households.

\section{References}

[1] Alberto Alesina and Dani Rodrik. Distributive Politics and Economic Growth. Quarterly Journal of Economics, 109:465-490, 1994.

[2] David Altig, Alan J. Auerbach, Laurence J. Kotlikoff, Kent A. Smetters, and Jan Walliser. Simulating U.S. Tax Reform. NBER Working Paper, 6248, 1997.

[3] Ken Binmore, Ariel Rubinstein, and Asher Wolinsky. The Nash Bargaining Solution in Economic Modelling. Rand Journal of Economics, 17:176-188, 1986.

[4] Christophe Chamley. Optimal Taxation of Capital Income in General Equilibrium with Infinite Lives. Econometrica, 54:607-622, 1986.

[5] V.V. Chari, Lawrence J. Christiano, and Patrick J. Kehoe. Optimal Fiscal Policy in a Business Cycle Model. Journal of Political Economy, 102:617-652, 1994.

[6] Thomas F. Cooley and Jorge Soares. Will Social Security Survive the Baby Boom? CarnegieRochester Conference Series on Public Policy, 45:88-121, 1996.

[7] Thomas F. Cooley and Jorge Soares. A Positive Theory of Social Security Based on Reputation. Journal of Political Economy, 107(1):135-160, 1999. 
[8] Mariacristina De Nardi, Selahattin İmrohoroğlu, and Thomas J. Sargent. Projected U.S. Demographics and Social Security. Review of Economic Dynamics, 2(3):575-615, 1999.

[9] Don Fullerton and Diane Lim Rogers. Who Bears the Lifetime Tax Burden? The Brookings Institution, 1993.

[10] Roger H. Gordon and Joel Slemrod. Do we Collect any Revenue from Taxing Capital Income? In Lawrence H. Summers, editor, Tax Policy and the Economy, volume 2, pages 89-130. National Bureau of Economic Research, 1988.

[11] He Huang, Selahattin İmrohoroğlu, and Thomas J. Sargent. Two Computations to Fund Social Security. Macroeconomic Dynamics, 1:7-44, 1997.

[12] Kenneth L. Judd. Redistributive Taxation in a Simple Perfect Foresight Model. Journal of Public Economics, 28:59-83, 1985.

[13] Laurence J. Kotlikoff. Generational Accounting: Knowing who Pays, and when, for what we Spend. Free Press, 1992.

[14] Laurence J. Kotlikoff, Torsten Persson, and Lars E.O. Svensson. Social Contracts as Assets: a Possible Solution to the Time-Consistency Problem. American Economic Review, 78:662677, 1988.

[15] Per Krusell, Vincenzo Quadrini, and José-Víctor Ríos-Rull. Politico-economic Equilibrium and Economic Growth. Journal of Economic Dynamics and Control, 21:243-272, 1997.

[16] Luisa Lambertini and Costas Azariadis. The Fiscal Politics of Big Governments: Do Coalitions Matter? Mimeo, University of California, Los Angeles, 1998.

[17] Casey B. Mulligan and Xavier X. Sala i Martin. Gerontocracy, Retirement and Social Security. NBER Working Paper, 7117, 1999.

[18] Casey B. Mulligan and Xavier X. Sala i Martin. Social Security in Theory and Practice (I): Facts and Political Theories. NBER Working Paper, 7118, 1999.

[19] Torsten Persson and Guido Tabellini. Is Inequality Harmful for Growth? American Economic Review, 84:600-621, 1994.

[20] Christopher Phelan and Ennio Stacchetti. Sequential Equilibria in a Ramsey Taxes Model. Federal Reserve Bank of Minneapolis Staff Report, 258, 1999.

[21] Thomas I. Renström. Endogenous Taxation: An Overlapping Generations Approach. Economic Journal, 106:471-482, 1996. 
Figure 1 - Stationary government policy as a function of current capital
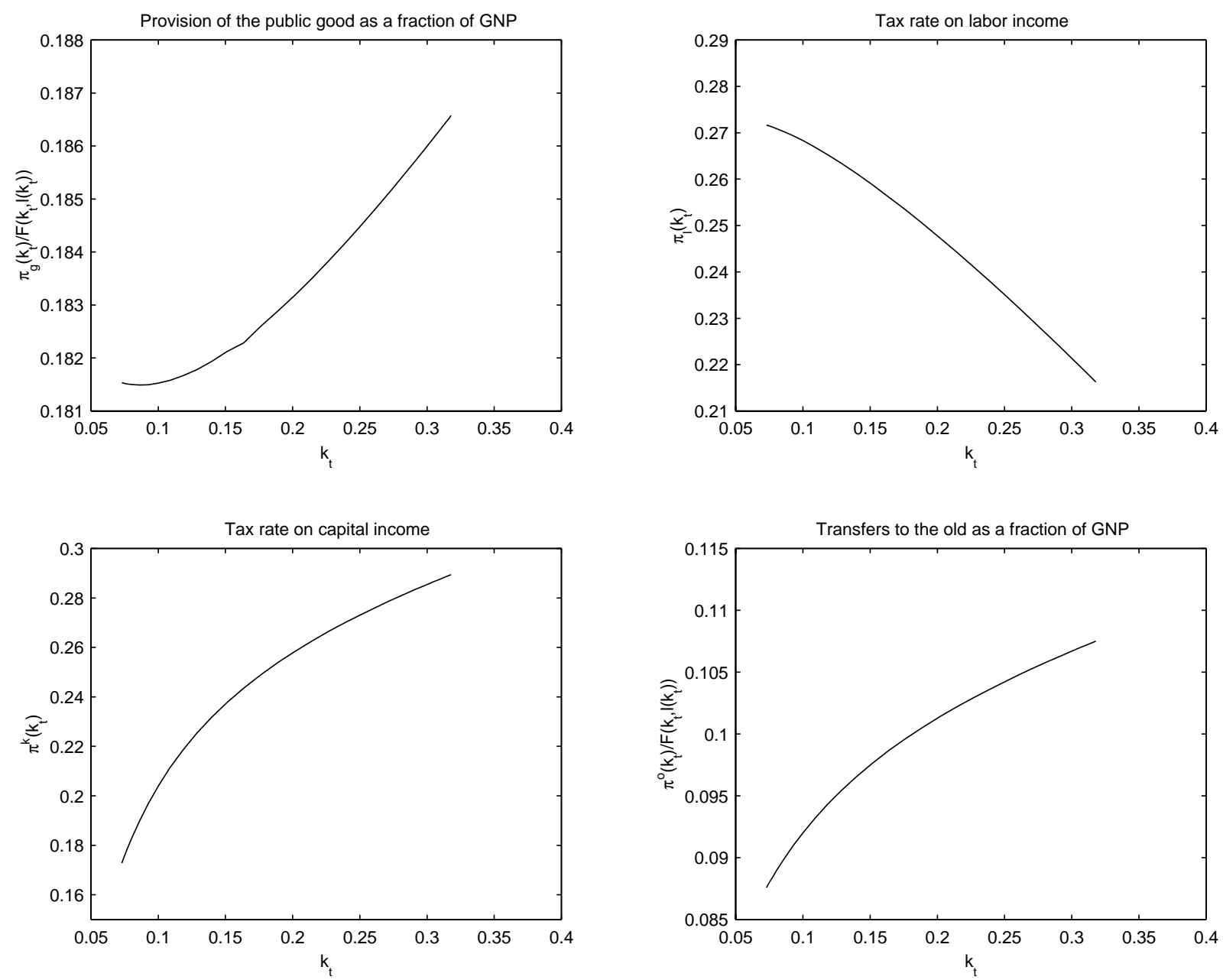
Figure 2 - Net contribution to the provision of the public good

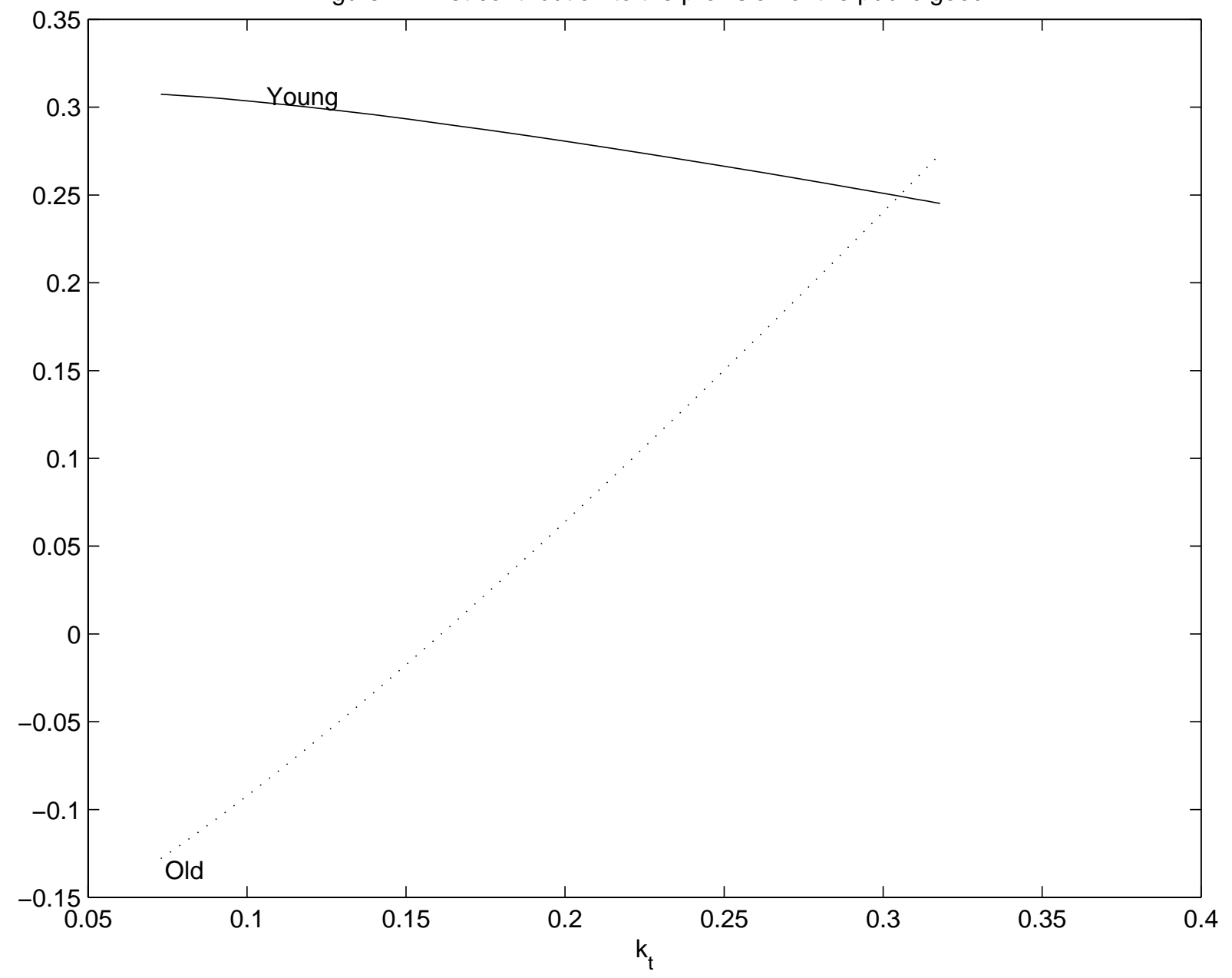


Figure 3 - Transition function for capital

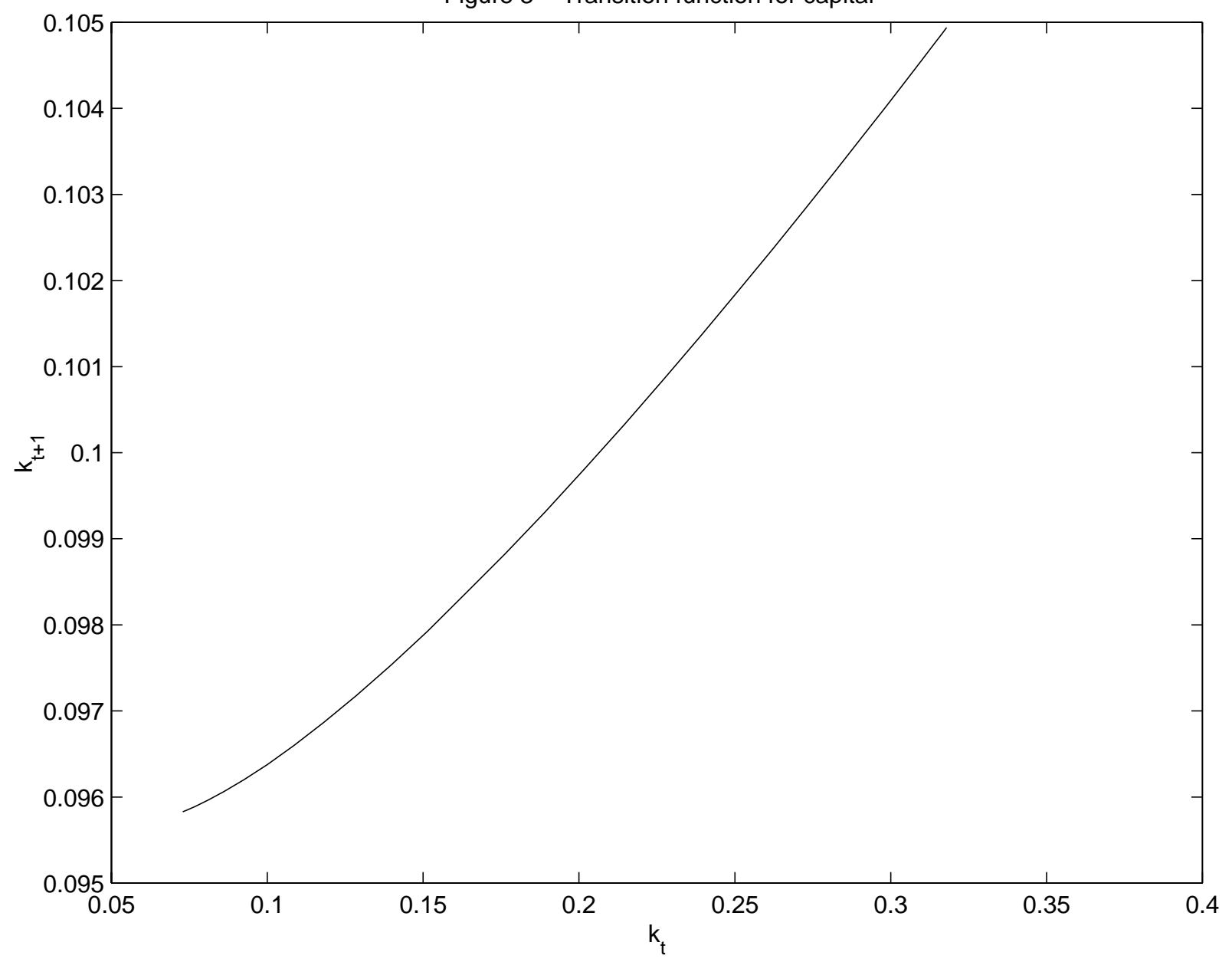


Figure 4 - Government policy in the transition, unanticipated case
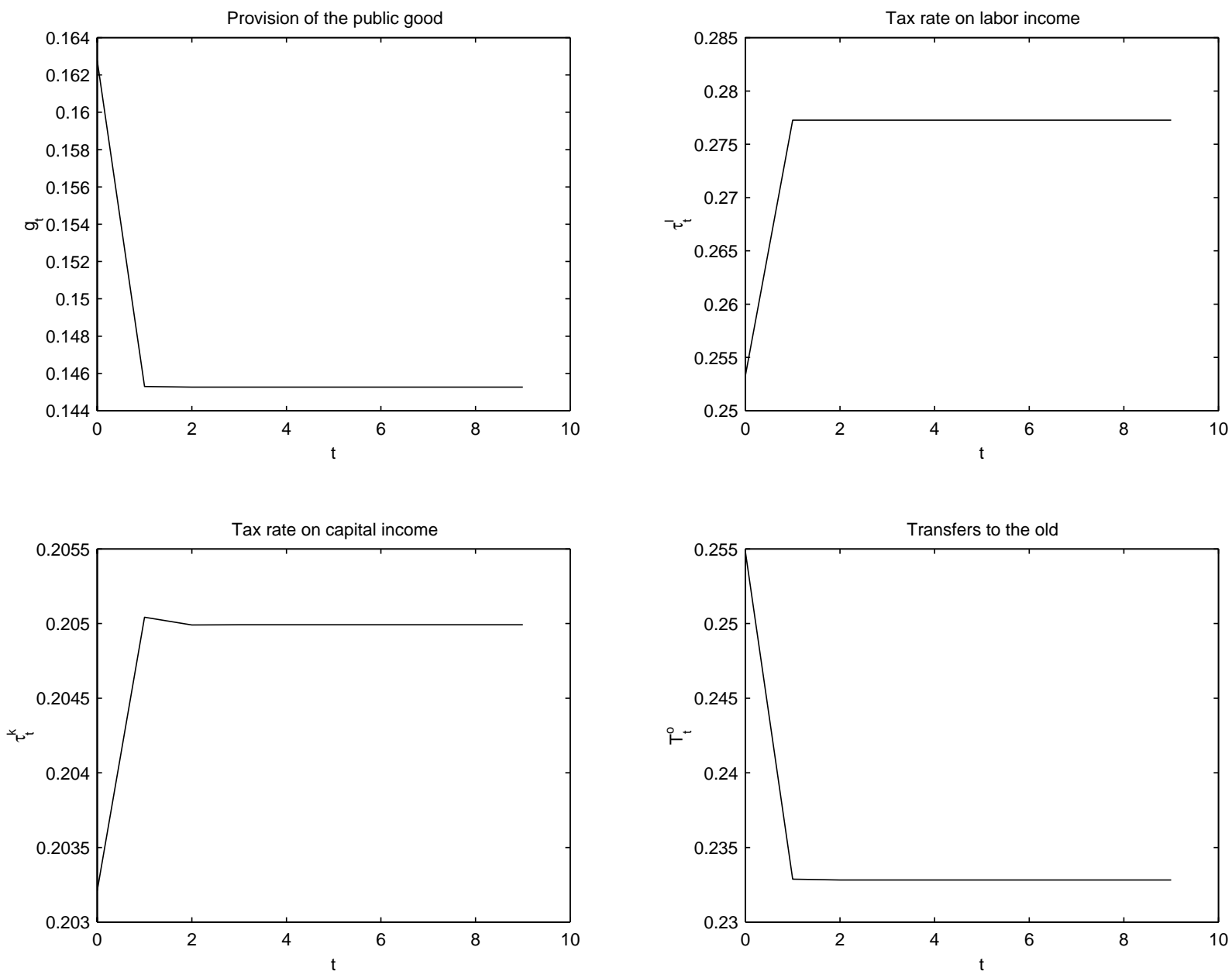
Figure 5 - Net contribution to $g_{t}$, unanticipated case

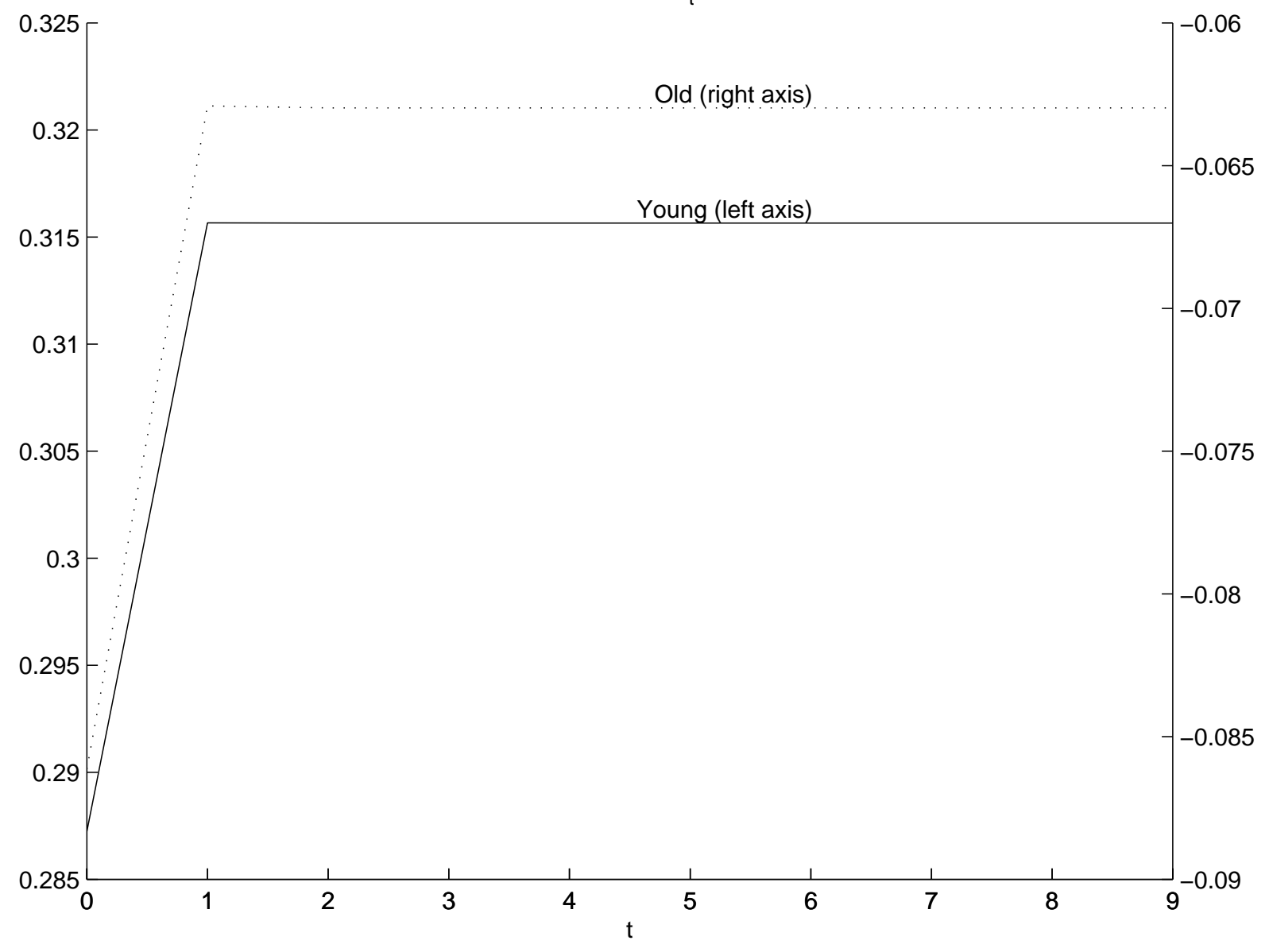




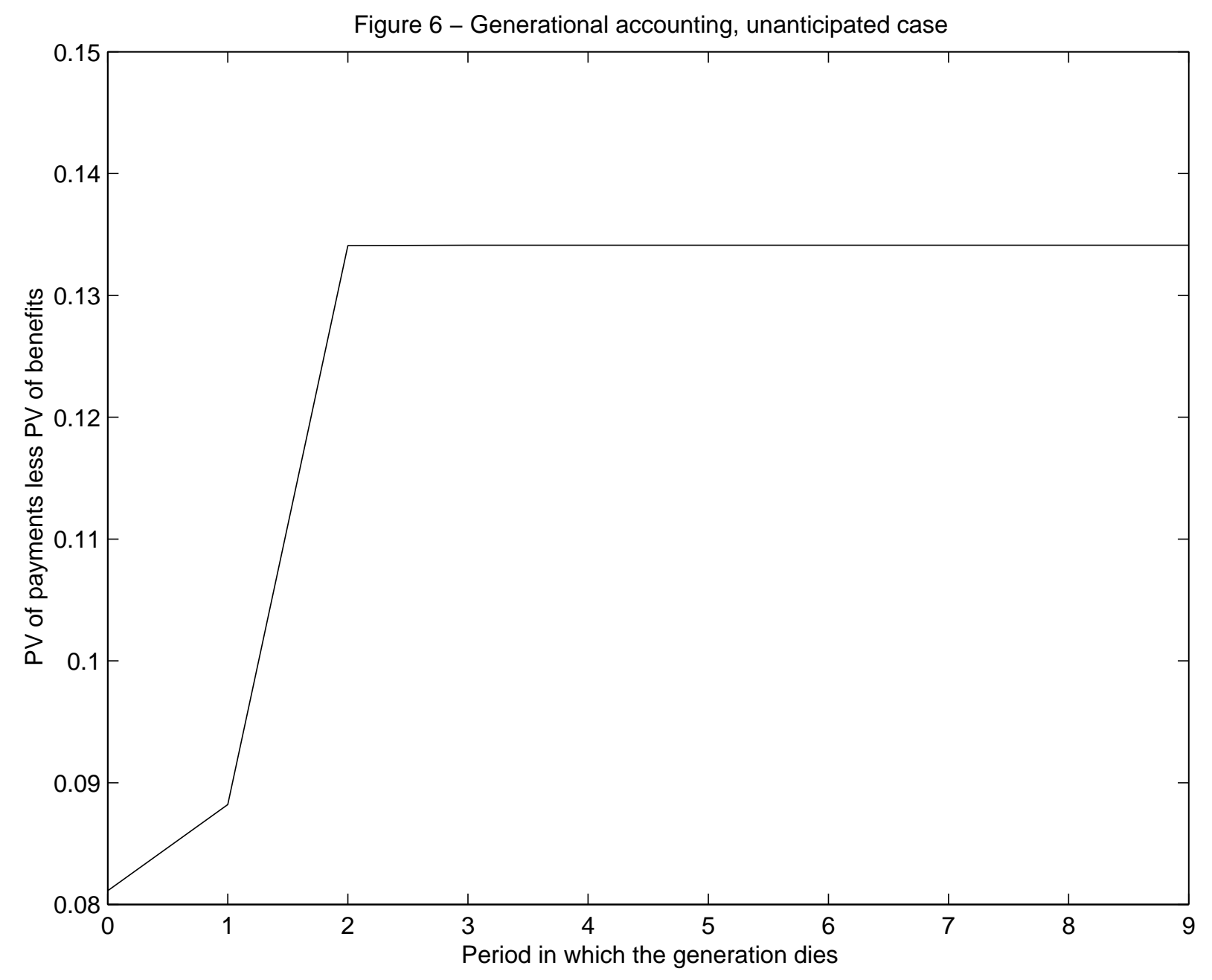


Figure 7 - Government policy in the transition, anticipated case
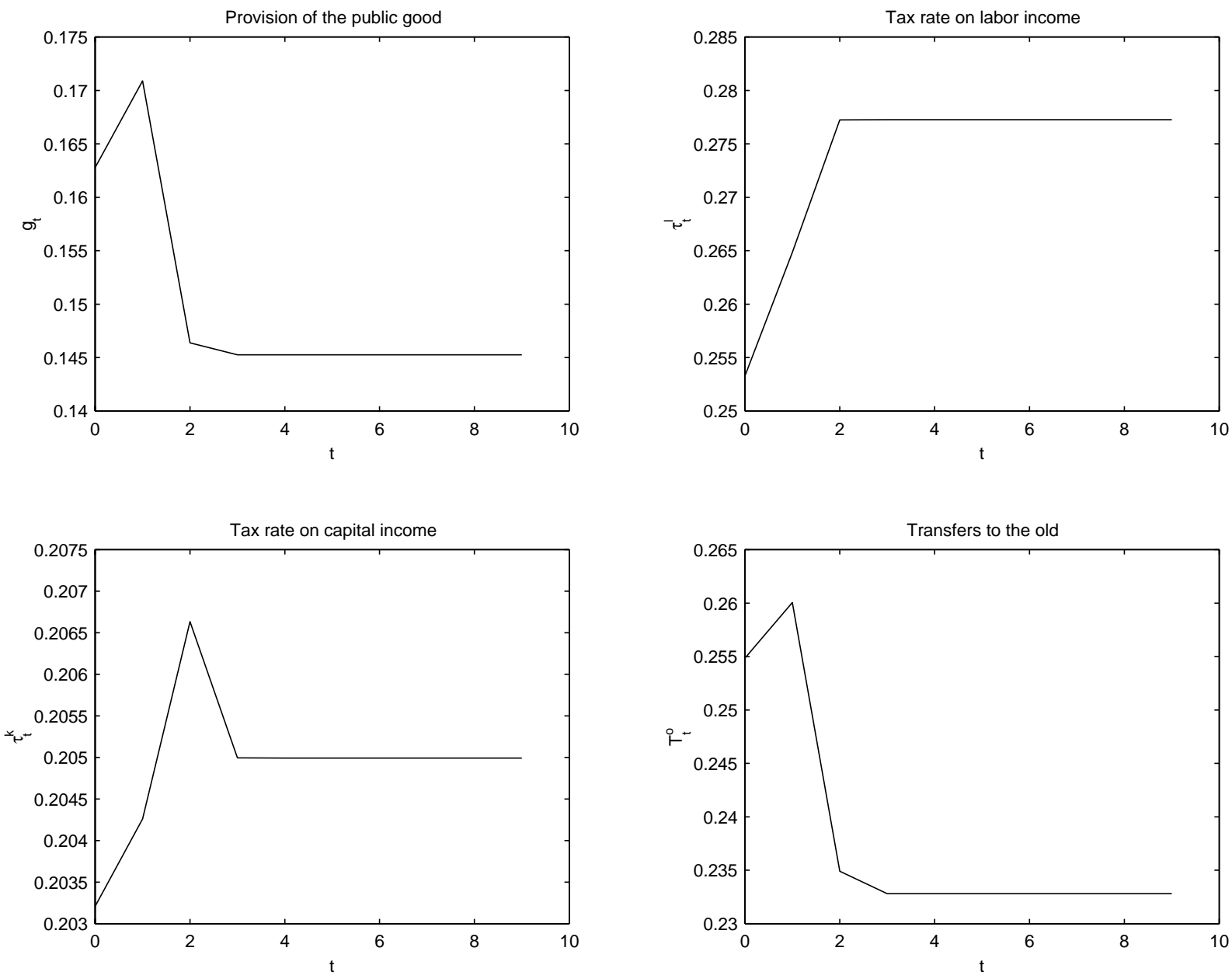
Figure 8 - Net contribution to $g_{t}$, anticipated case

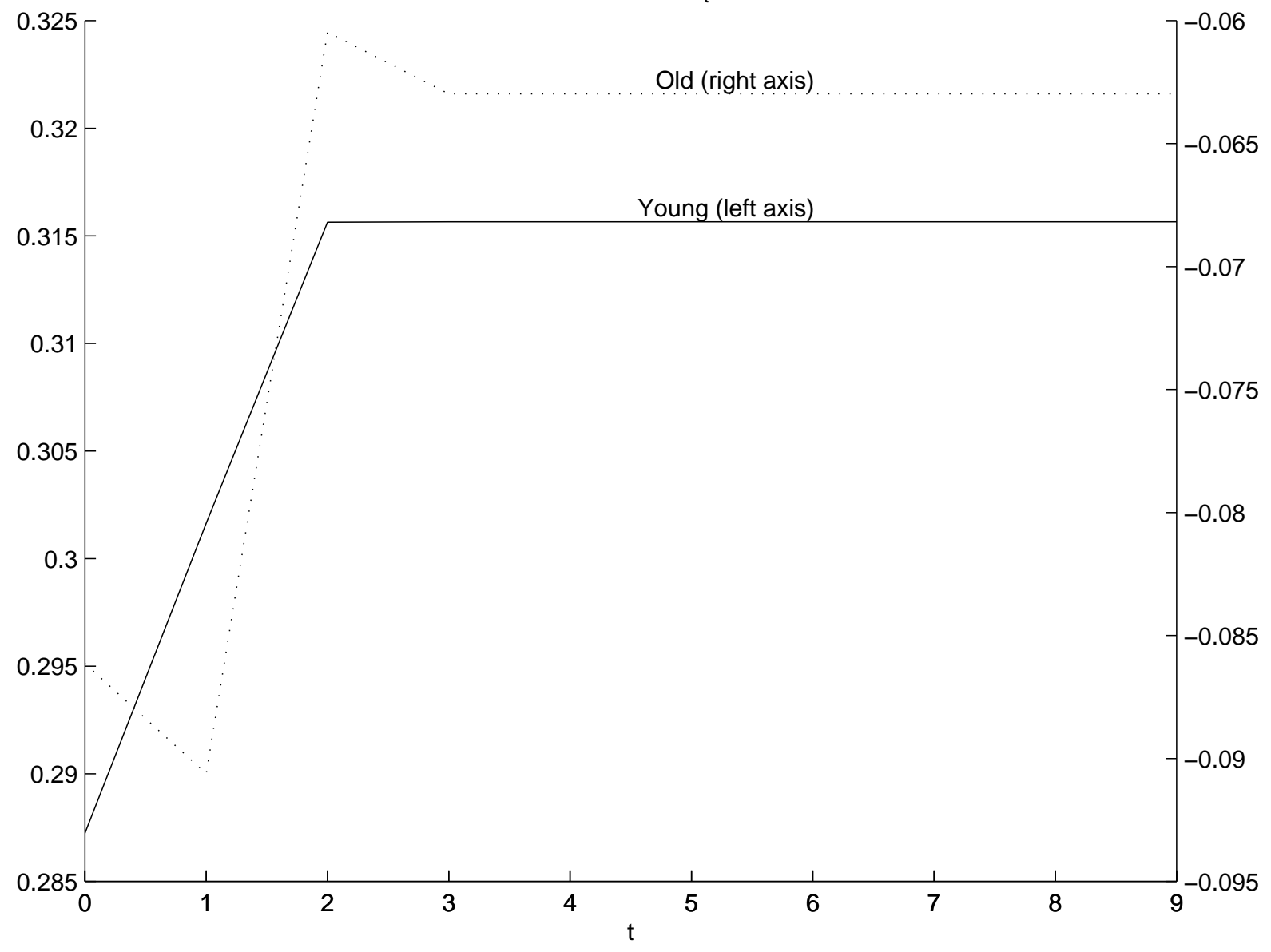


Figure 9 - Capital over time, anticipated case

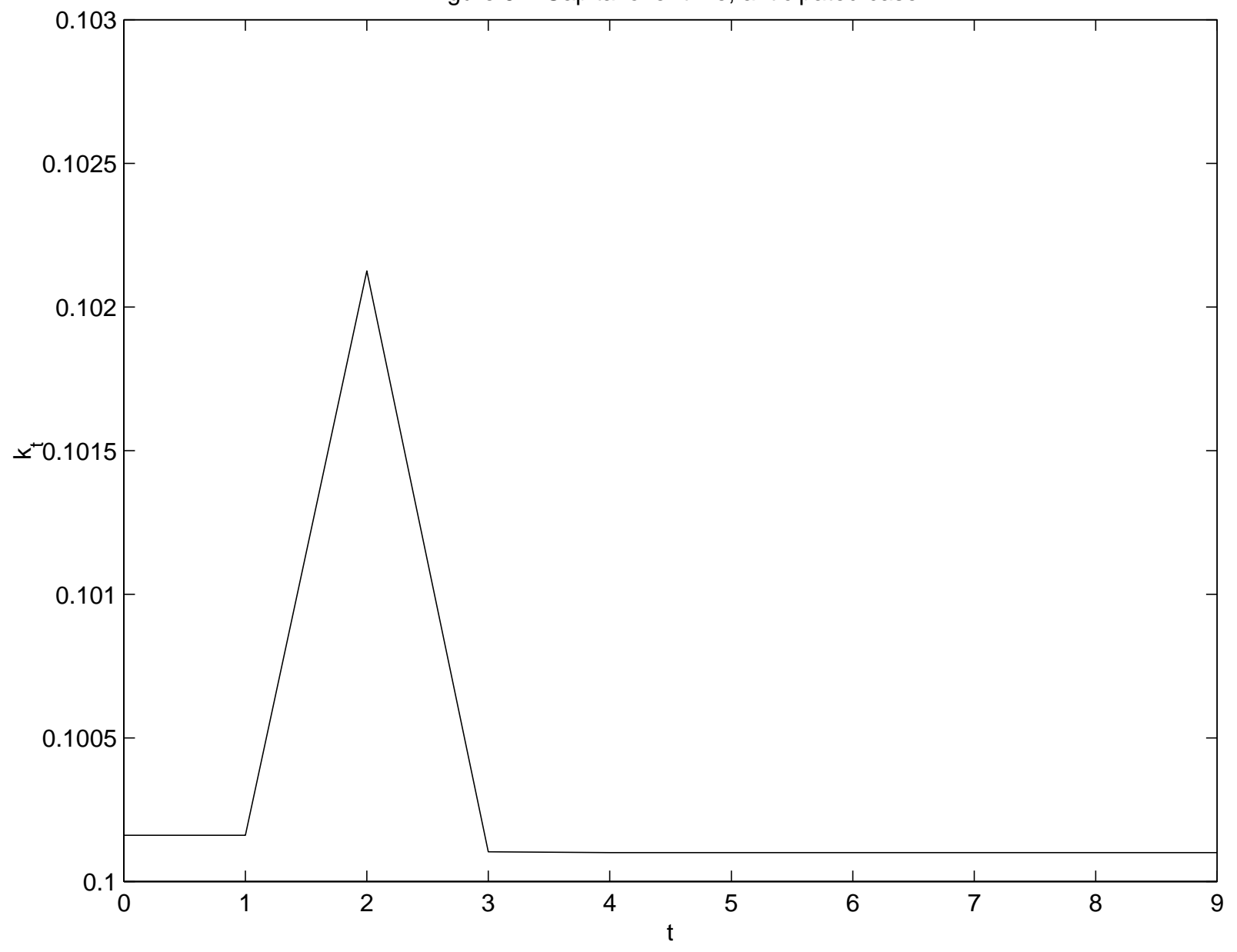


Figure 10 - Generational accounting, anticipated case

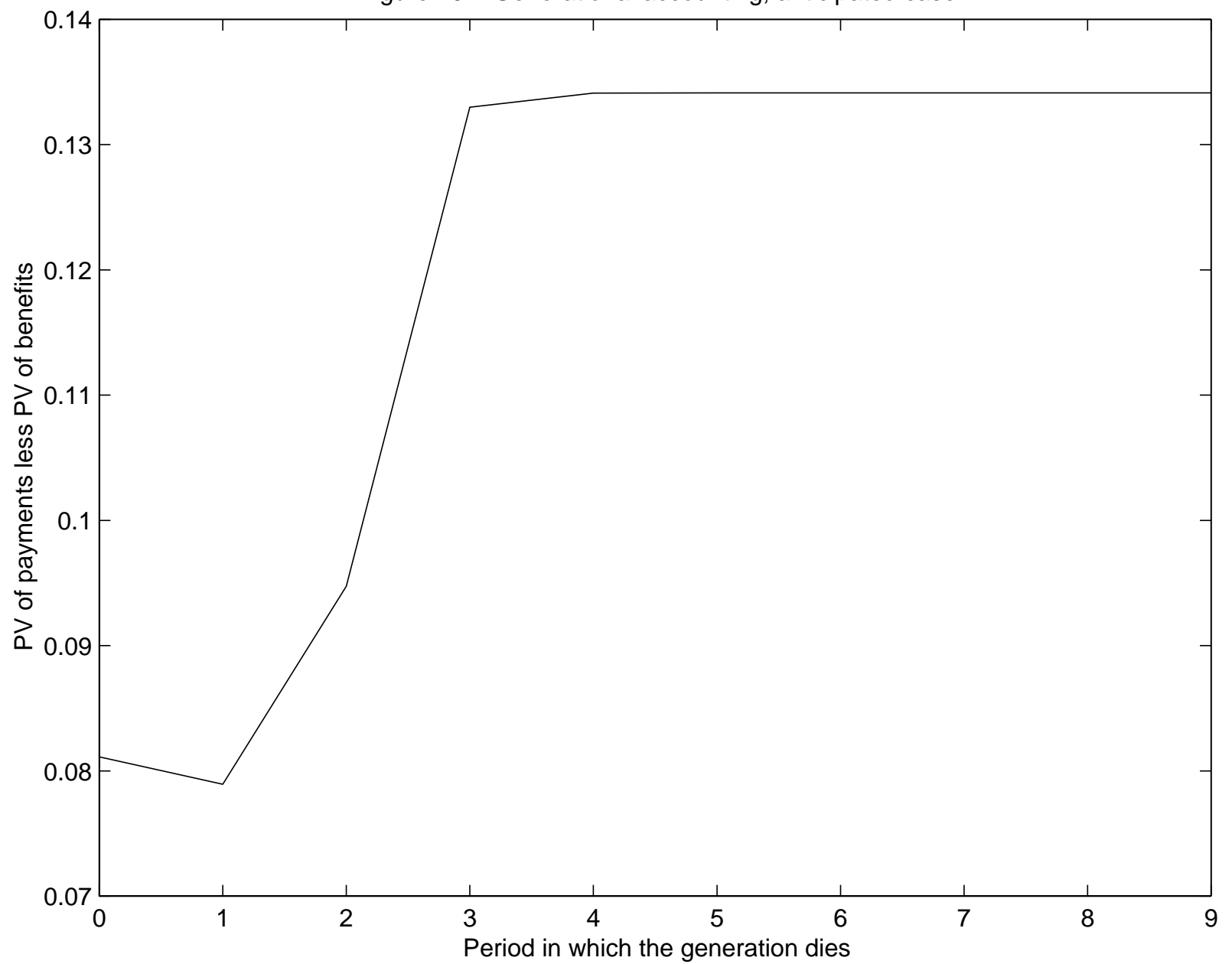


Figure 11 - Stationary government policy as a function of current capital with endogenous prices
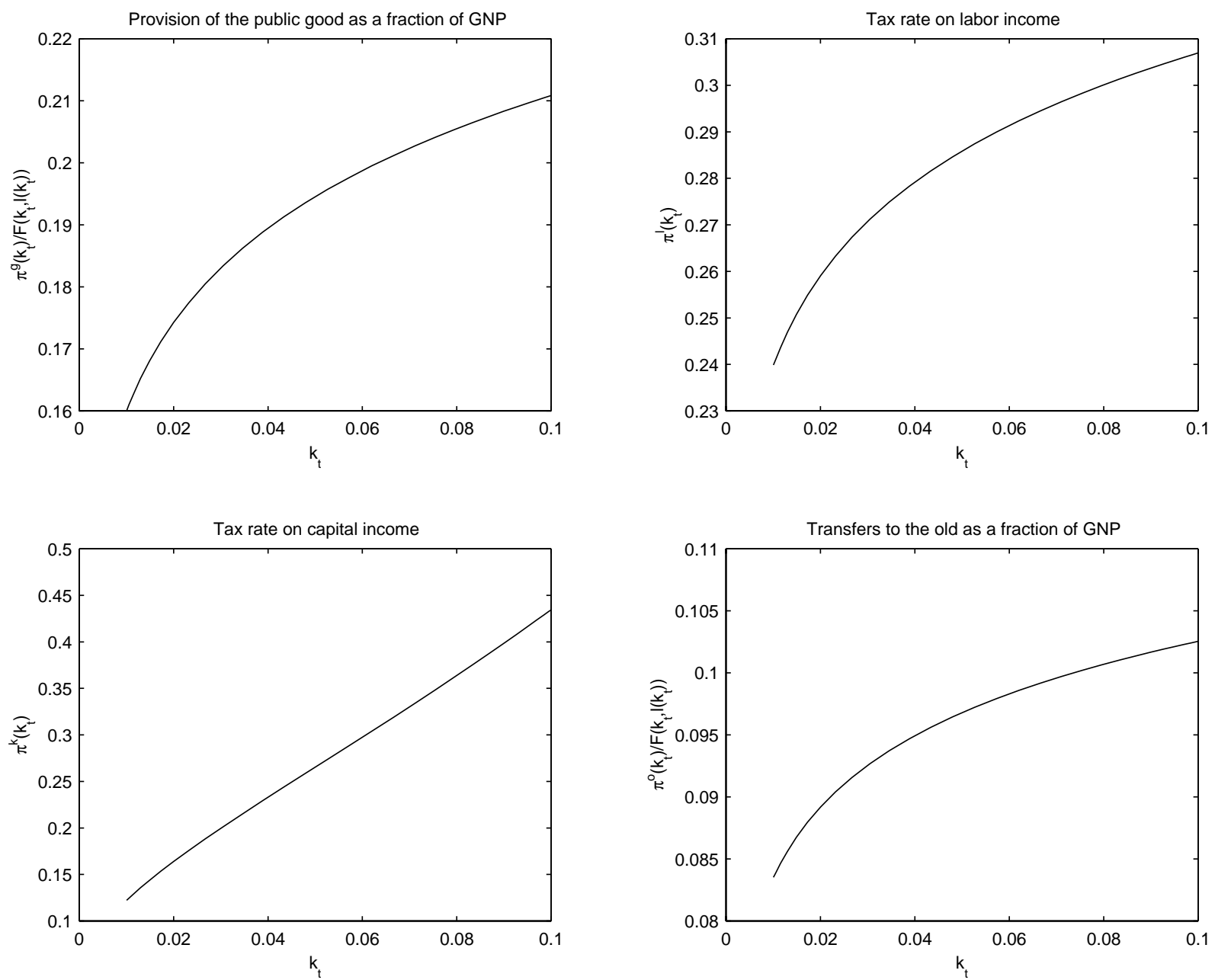
Figure 12 - Factor prices as a function of current capital with endogenous prices
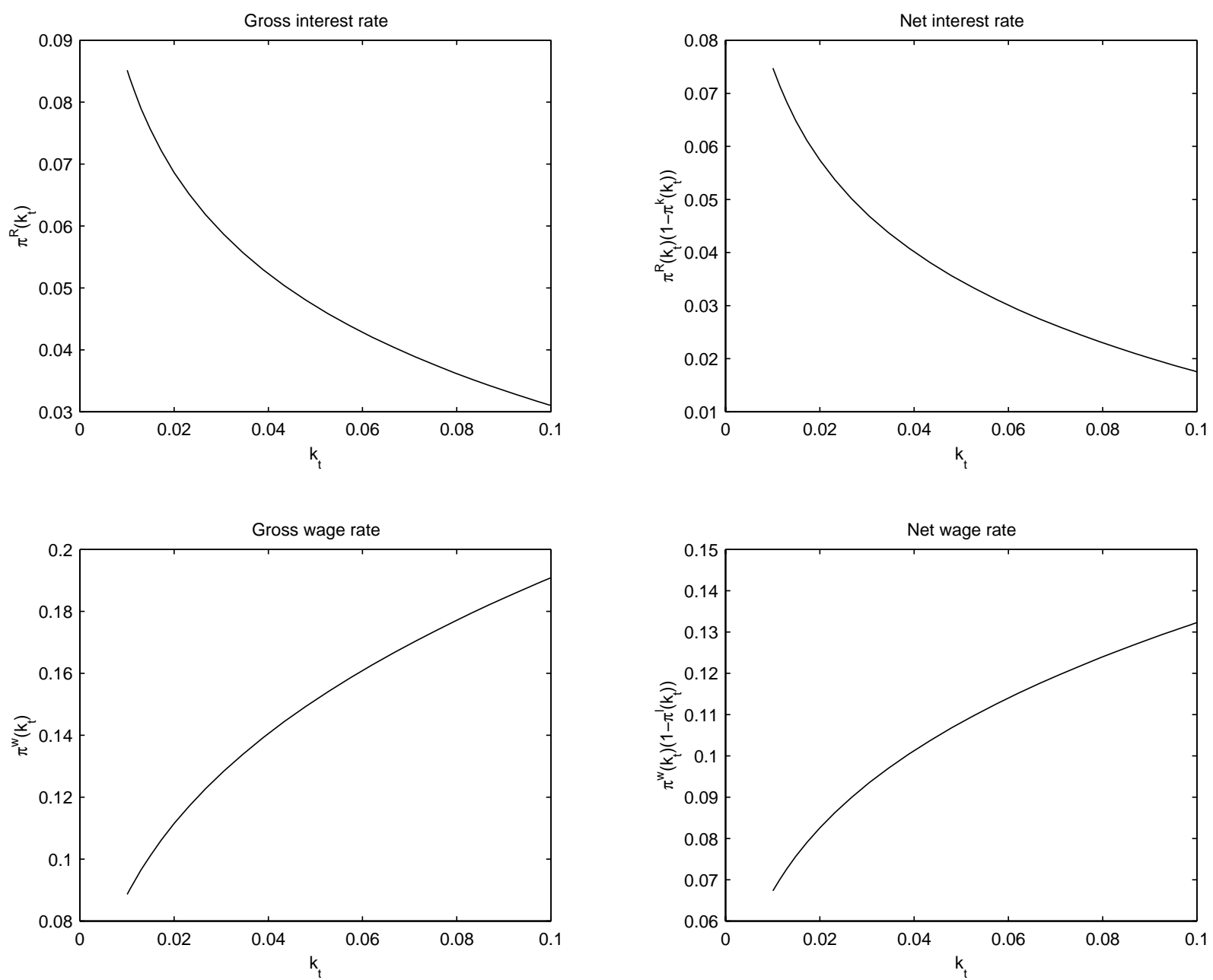
Figure 13 - Net contribution to the provision of the public good with endogenous prices

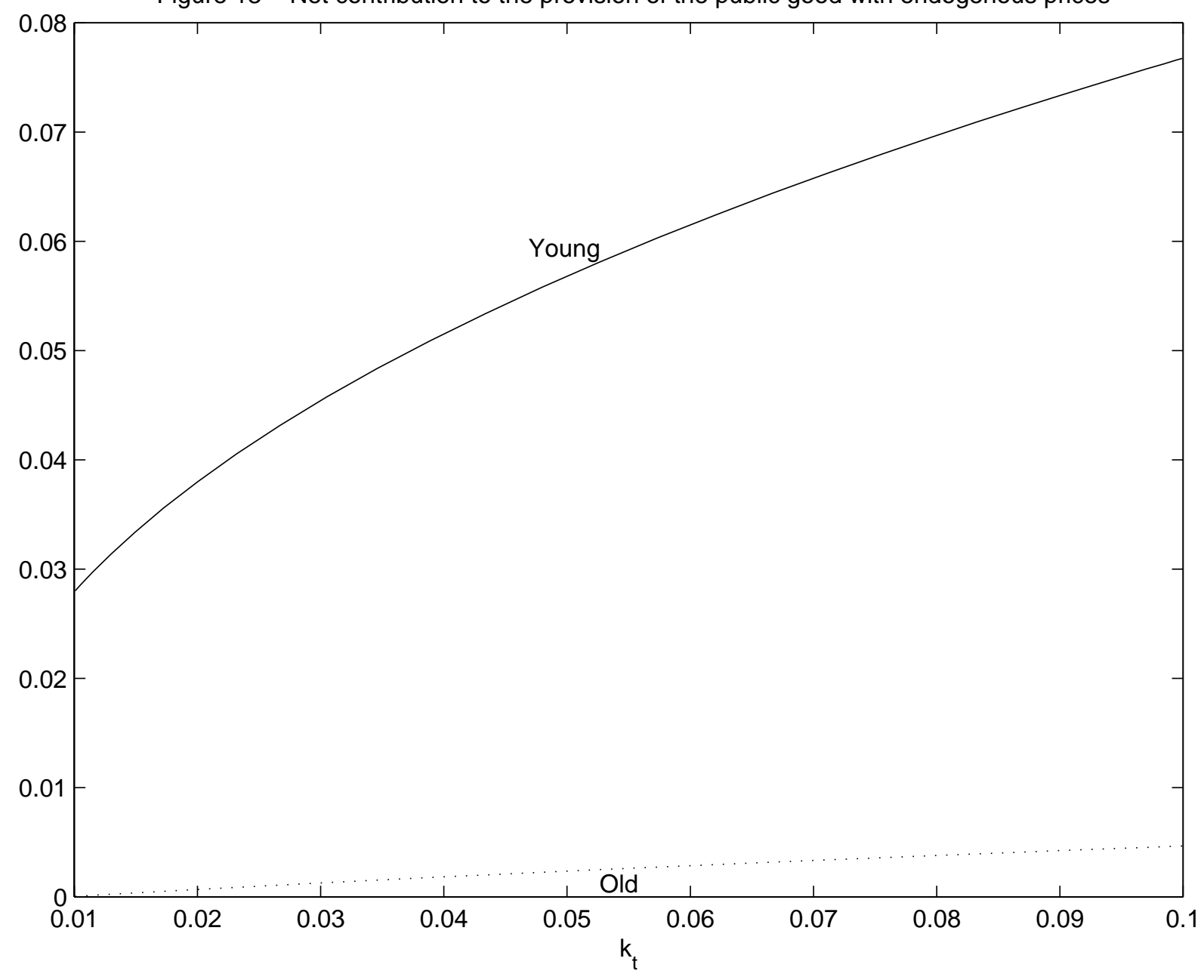




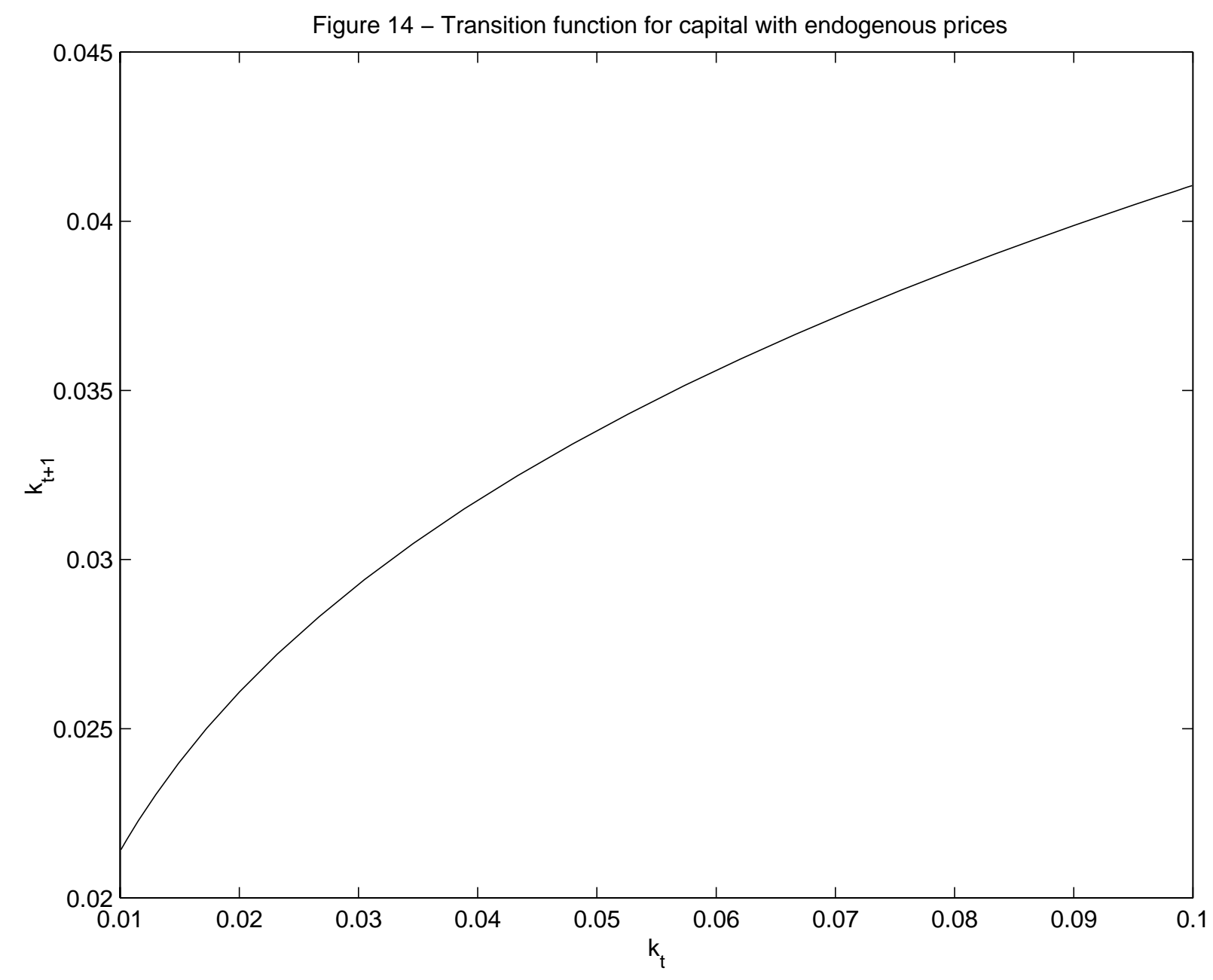


Figure 15 - Government policy in the transition, unanticipated case with endogenous prices
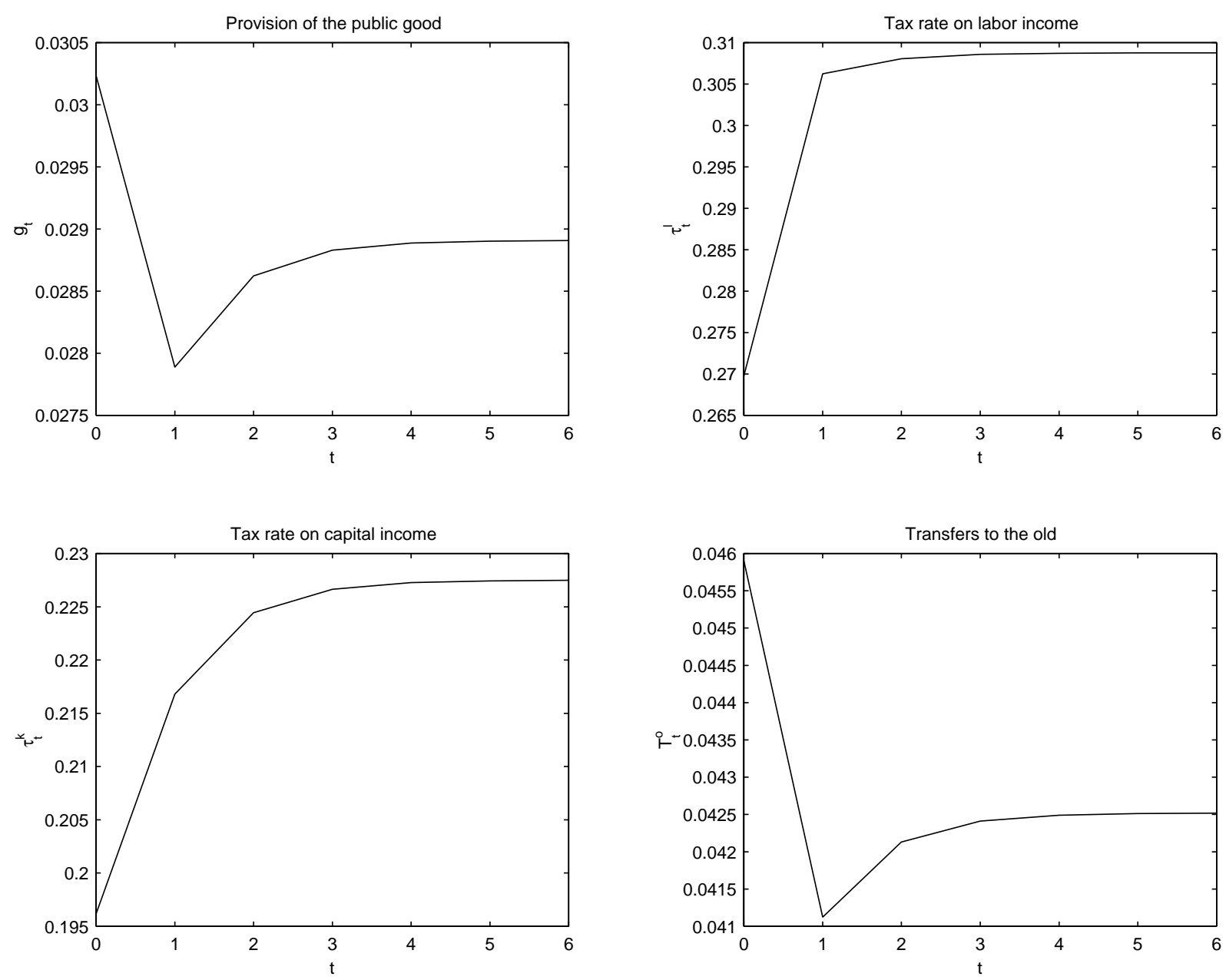
Figure 16 - Factor prices in the transition, unanticipated case with endogenous prices
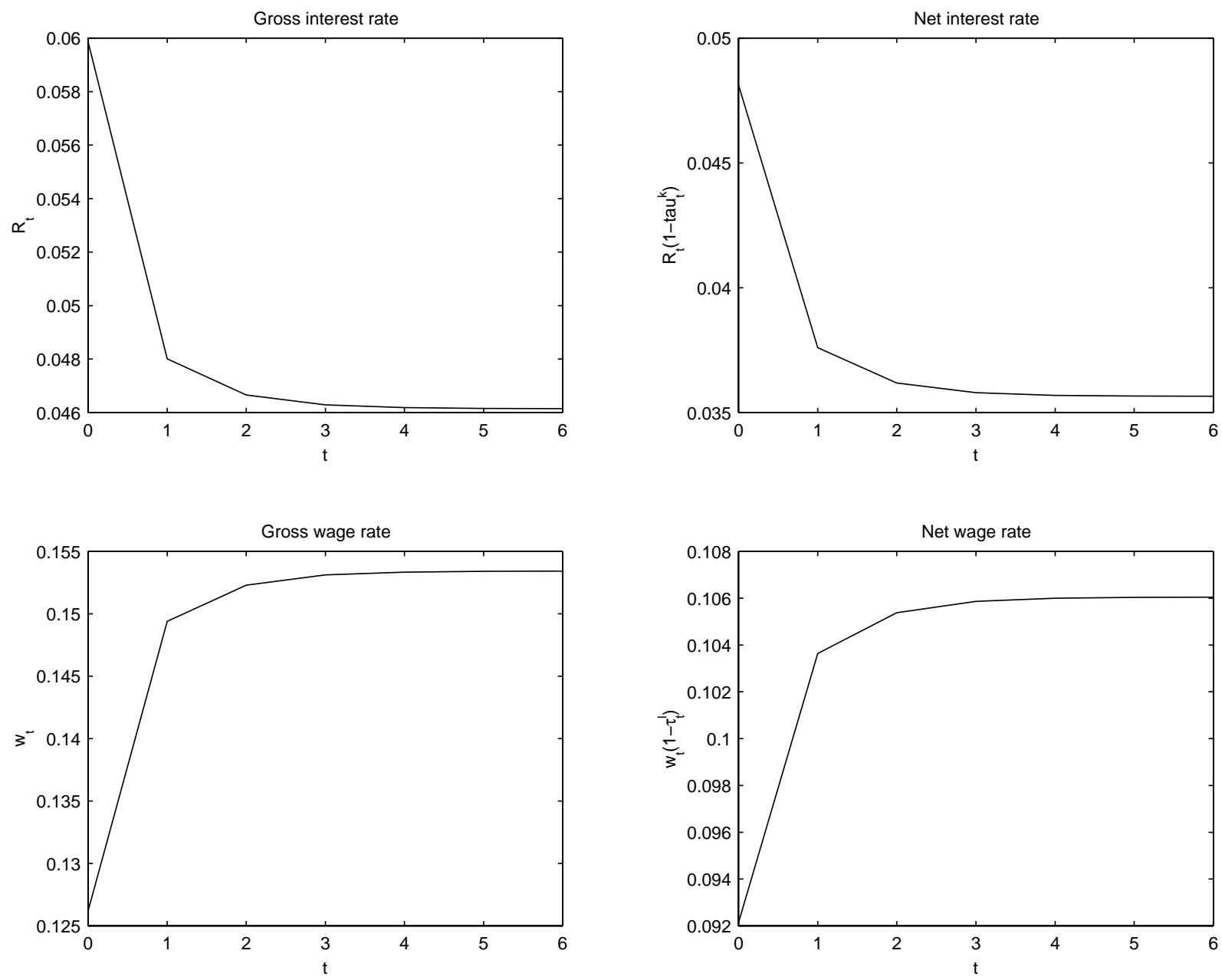


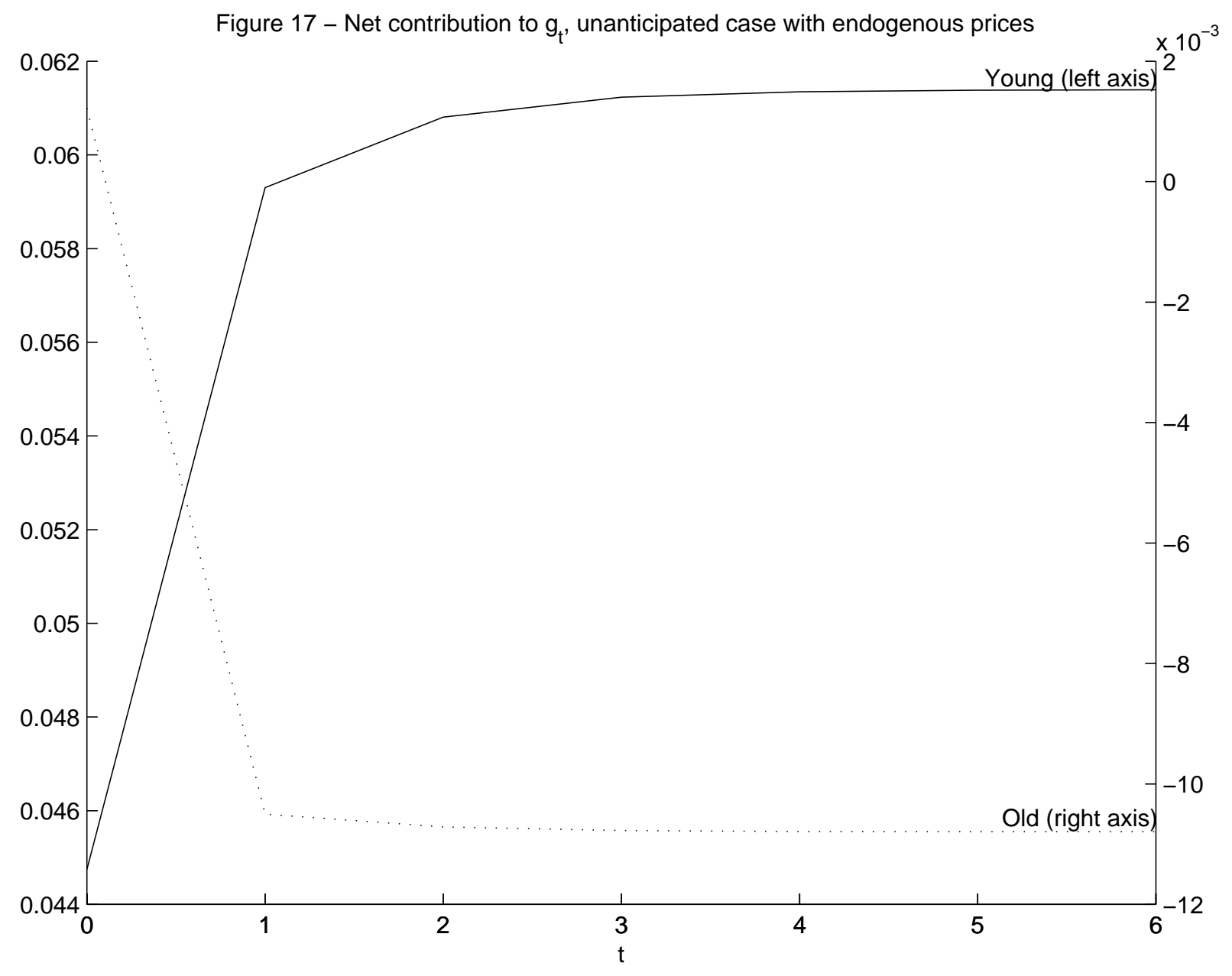


Figure 18 - Government policy in the transition, anticipated case with endogenous prices
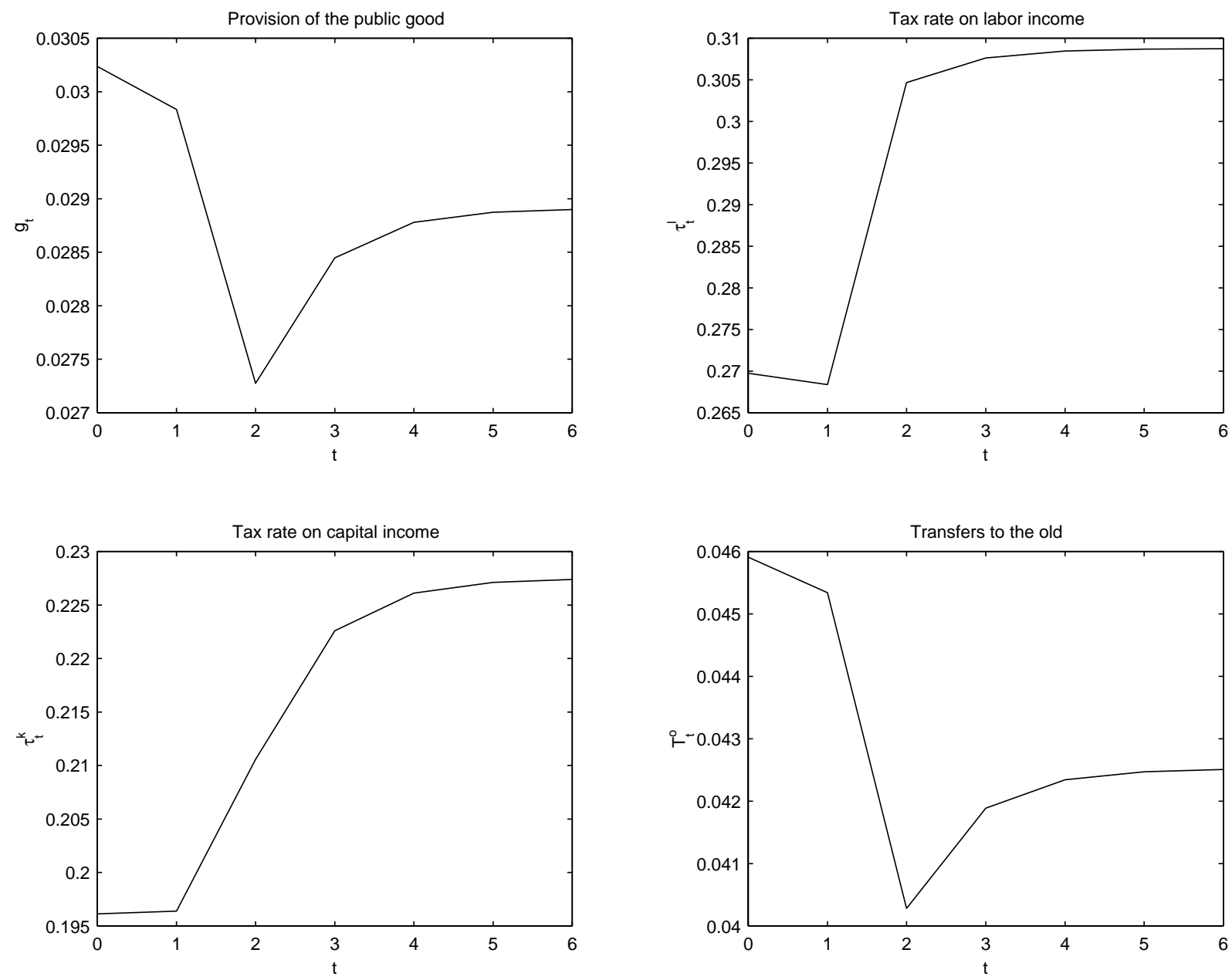
Figure 19 - Factor prices in the transition, anticipated case with endogenous prices
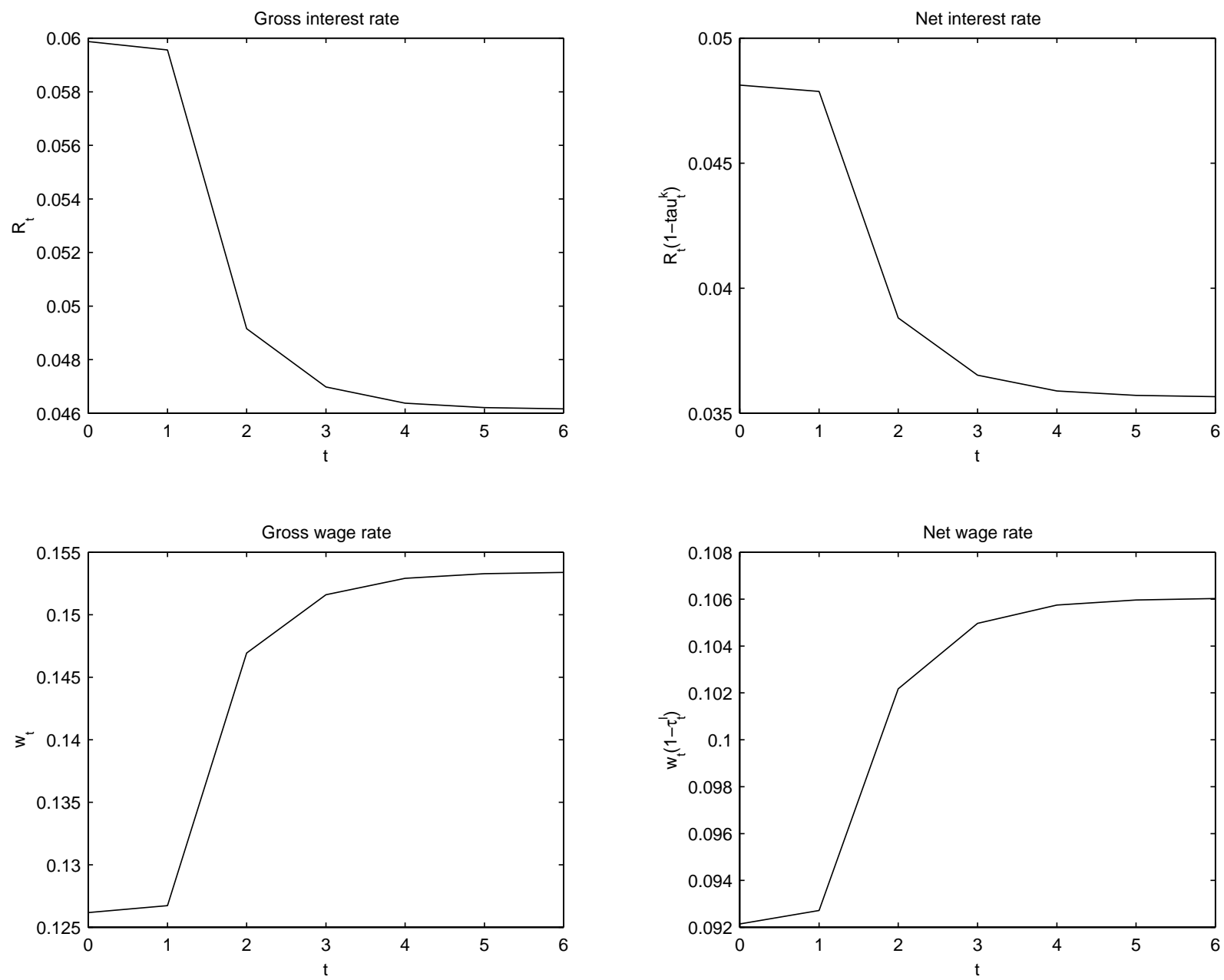
Figure 20 - Net contribution to $g_{t}$, anticipated case with endogenous prices

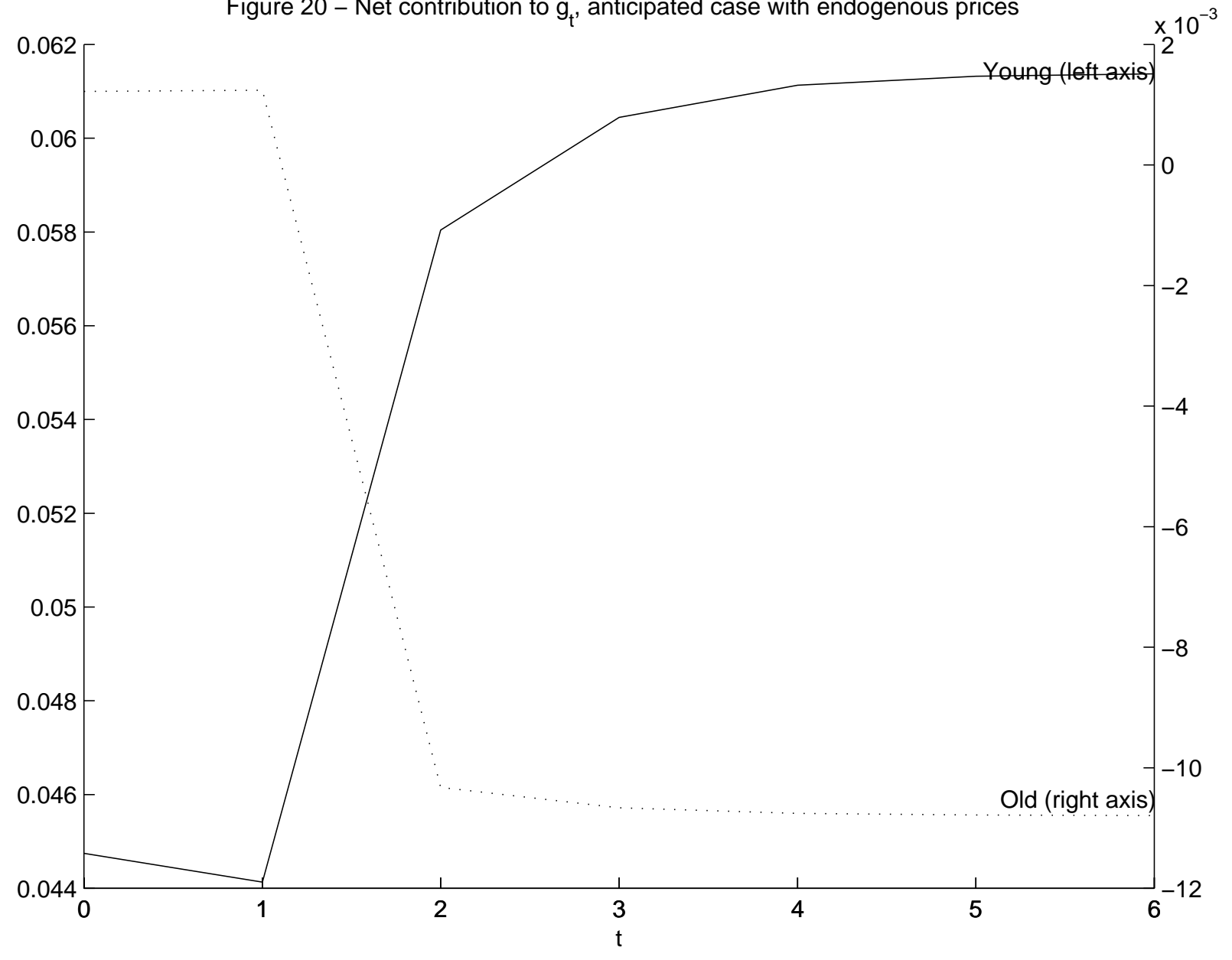

